\title{
Skills Shortages and Training in Russian Enterprises ${ }^{1}$
}

\author{
Hong Tan and Yevgeniya Savchenko \\ World Bank, Washington DC
}

and

\author{
Vladimir Gimpelson, Rostislav Kapelyushnikov and Anna Lukyanova \\ Higher School of Economics, Moscow
}

\begin{abstract}
In the transition to a market economy, the Russian workforce underwent a wrenching period of change, with excess supply of some industrial skills coexisting with reports of skills shortages by many enterprises. This paper uses data from the Russia Competitiveness and Investment Climate Survey and related local research to gain insights into the changing supply and demand for skills over time, and the potential reasons for reported staffing problems and skills shortages, including labor turnover, compensation policies and the inhibiting effects of labor regulations. It discusses inservice training as an enterprise strategy for meeting staffing and skills needs, and presents evidence on the distribution, intensity and determinants of in-service training in Russia. It investigates the productivity and wage outcomes of in-service training, and the supportive role of training in firms' research and development (R\&D) and innovative activities. A final section concludes with some policy implications of the findings.

World Bank Policy Research Working Paper 4222, May 2007

The Policy Research Working Paper Series disseminates the findings of work in progress to encourage the exchange of ideas about development issues. An objective of the series is to get the findings out quickly, even if the presentations are less than fully polished. The papers carry the names of the authors and should be cited accordingly. The findings, interpretations, and conclusions expressed in this paper are entirely those of the authors. They do not necessarily represent the view of the World Bank, its Executive Directors, or the countries they represent. Policy Research Working Papers are available online at http://econ.worldbank.org.
\end{abstract}

\footnotetext{
${ }^{1}$ This paper was prepared as part of a World Bank-Higher School of Economics joint study conducted in 2005-2006, that is being published as a World Bank report, "Building Skills and Absorptive Capacity in Russian Enterprises", forthcoming 2007.
} 


\section{Skills Shortages and Training in Russian Enterprises}

\section{Introduction}

Russia, despite having a highly educated workforce, now faces a looming skills crisis in industry. In the transition to a market economy, the Russian workforce underwent a wrenching reallocation of labor across industries and occupations, ${ }^{2}$ and many specialized and technical skills previously acquired under central planning became partially or fully depreciated, and were no longer demanded by industry. Mismatches in the labor market became widespread, with sharp shortages of some types of skilled workers coexisting with excess supplies of others. The formal education system and the specialized vocational and technical training institutions in particular were poorly prepared to operate under these new market conditions and to supply the new skills required by the market. Employers who used to hoard labor are now increasingly reporting skills shortages as a major production constraint, and some are upgrading the skills of their existing workers through in-service training programs.

Analyzing these skills issues and developing policies to address them are critically important if Russia is to raise labor productivity in industry, improve its international competitiveness, and participate more fully in the Knowledge Economy. Skills shortages directly constrain production, and prevent firms from meeting demand and using available inputs efficiently with consequences for lower productivity; indirectly, skills shortages can inhibit innovation and use of new technologies which are skill-intensive activities. Skills mismatches, between the skills that firms require and what education and training institutions supply to the labor market, have implications for the wasteful use of scarce public and private resources and, for individuals, sunk investments in their human capital that yield low returns and unfavorable labor market outcomes. What policies are appropriate will depend on the proximate causes of skills mismatches, whether under-funding or the governance of education and training institutions that constrain them from responding to the skills needs of the market; labor regulations that inhibit hiring and firing by firms to meet staffing shortfalls or compensation policies that prevent some employers from paying competitive wages to attract needed labor; or market failures in the training market, such as high turnover of trained workers, that inhibit the willingness of employers to invest in training and upgrade worker skills to meet their own skills needs.

This paper uses the 2005 Russia Competitiveness and Investment Climate Survey ${ }^{3}$ (henceforth, referred to as ICS) and related local research and information sources to gain insights into these issues of skills shortages, skills mismatches and in-service training in Russia. Section II examines the macro trends in the levels and quality of education, the effects of economic restructuring on the skills composition of the workforce during the

\footnotetext{
${ }^{2}$ According to K.Sabirianova (2001), over 40 percent of all the employed in Russia changed their occupations during the 1991-1998 period and two thirds of them did it within 1991-95. She termed this mass occupational change that took place the "Great Human Capital Reallocation".

${ }^{3}$ The Russian ICS consists of two parts: the Russian Large and Medium Enterprise Survey (LME) covering 1000 firms, and the Russian Small Enterprise Survey (SE) covering 300 firms.
} 
transition period, the returns to schooling and what these macro trends suggest about aggregate supply and demand for skills in the Russian labor market. Section III uses data from firm surveys, including the Russia ICS, to characterize the distribution and nature of staffing and skills shortages among different groups of manufacturing firms. These micro data are analyzed to gain insights into the potential reasons for reported staffing problems and skills shortages, including labor turnover, compensation policies and the inhibiting effects of labor regulations. Section IV turns to a discussion of worker training as a strategy for enterprises to meet their staffing and skills needs, and presents evidence on the distribution, intensity and determinants of in-service training in Russia. Section V investigates the productivity and wages outcomes of in-service training, and the supportive role of training in firms' research and development (R\&D) and innovative activities. A final section concludes with some policy implications of the findings.

\section{Macro Skills Trends during the Transition}

The evolution of human capital in Russia is closely associated with the transition from a centrally-planned economy to a market-oriented one. In the pre-transition period, most of Russia's workforce was concentrated in industry while the service sector was underdeveloped. Educational attainment was high but the educational system was oriented towards providing narrowly defined technical skills at the expense of more general knowledge and skills. Wage inequality was artificially compressed and rates of return to higher education were relatively low (in the 1-2 percent range).

This employment structure changed dramatically in 1991. In the first stage of the transition (1991-1998), industrial restructuring was accompanied by decreases in employment and working hours, unemployment growth, and steep decline in real wages. The second stage (1999-2006) developed against the background of a dynamic post-crisis recovery, which positively affected all labor market indicators, leading to rising returns to education and increasing reports from industry of skills shortages. These changes provide the backdrop for the following discussion of the macro trends in human capital accumulation.

\section{Stocks of Human Capital}

According to (Barro and Lee, 2001), Russia in 2001 had one of the most highly educated workforces in the world. For the population aged 25 and over, Russia ranked seventh in the Barro-Lee sample of countries with an average of 10.5 years of schooling. On a graph comparing the educational attainment and GDP per capita of the Barro-Lee countries, Russia is an outlier. See Figure 1. It is significantly above the fitted-line in the first panel, comparing mean years of educational attainment. Russia is ahead of other BRIC (Brazil, Russia, India and China) and transition countries as well as most OECD countries, leading Germany by 0.7 years, Japan by 0.8 years, and the U.K. by 1.1 years; only the U.S. is ahead of Russia, and the difference is about 1.8 years of education. 
Figure 1. International Comparisons of Educational Attainment

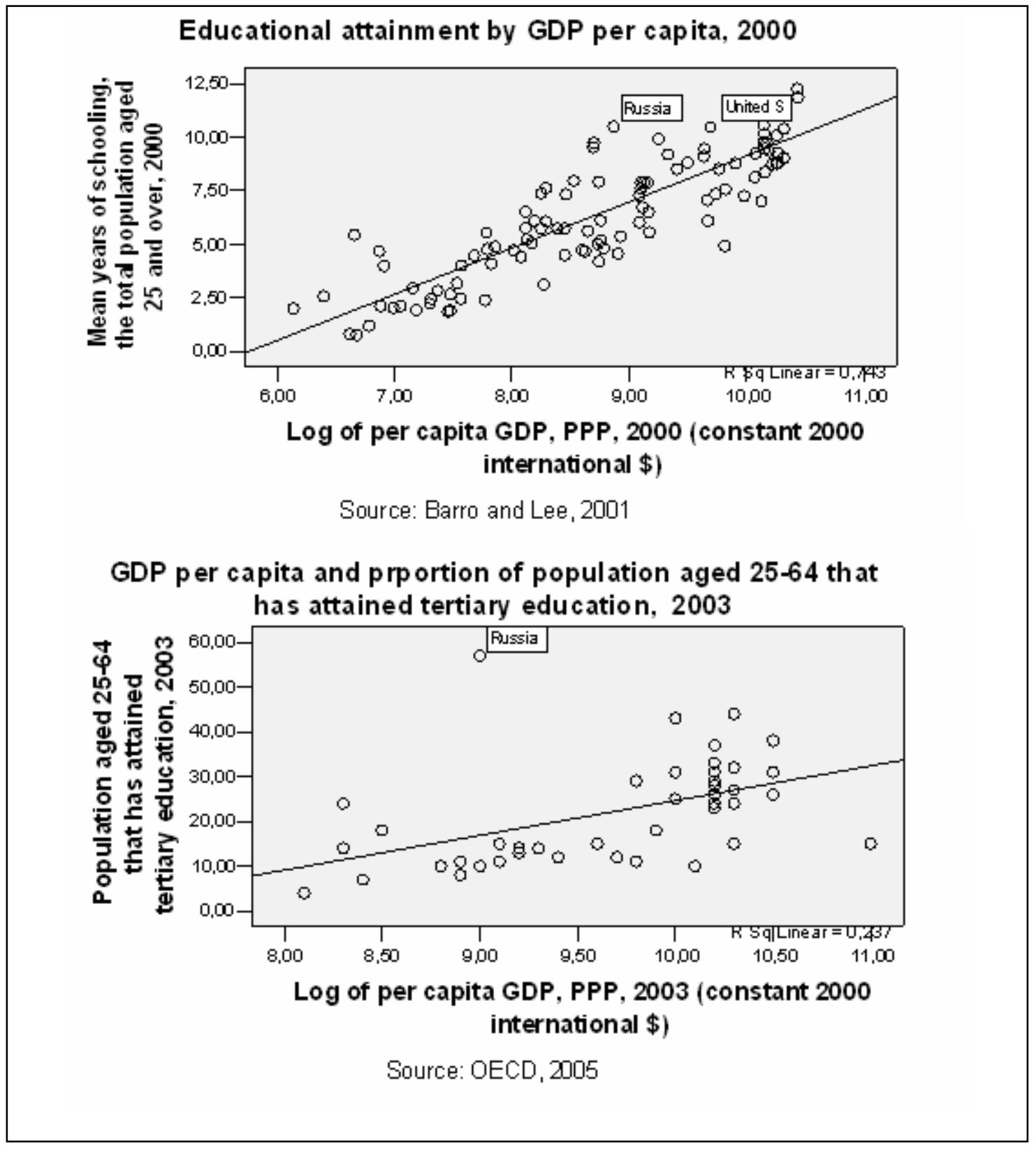

Russia also has one of the highest shares of population age 25 and over with tertiary education. See the bottom panel of Figure 1. Over half ( 57 percent) of the population has attained tertiary education, which is 13 percentage points more than in Canada and more than twice that in other post-socialist countries where the proportion of the population does not exceed 15 percent. This result is due in part to the very high proportion of the population that attended professional and technical colleges (or SSUZ in Russian). However, if only attendance at university-level institutions (or VUZ in Russian) is considered, Russia with 21 percent still ranks in the top 10 countries, sharing $9^{\text {th }}$ and $10^{\text {th }}$ place honors with Japan. 
Russia thus appears on the surface to be well situated to take advantage of knowledgebased economic activities requiring a well-educated workforce and a pool of researchers. Compared to BRIC and other transition countries, Russia in 2003 had twice as many researchers per million of population $(3,371)$ as compared to the Czech Republic, Hungary or Poland (averaging about 1,500), and 5 to 10 times more researchers than Brazil (344 in 2000) or China (663). On this indicator, Russia is closer to France and Germany (with about 3,200) but behind the U.S. and Japan $(4,500$ to 5,300). It has benefited from downsizing in the science sector during the transition so that a significant proportion of the workforce has experience in research activities.

\section{Quality of Education}

Its educational achievements notwithstanding, Russia fares less well internationally with regards to spending on education, with negative implications for the quality of education. In Russia, the share of total educational expenditures in GDP (3.7 percent) is lower than in developed and other transition countries, but comparable to educational spending in the BRIC countries (see Table 1).

Table 1. Expenditures on Educational Institutions, 2002

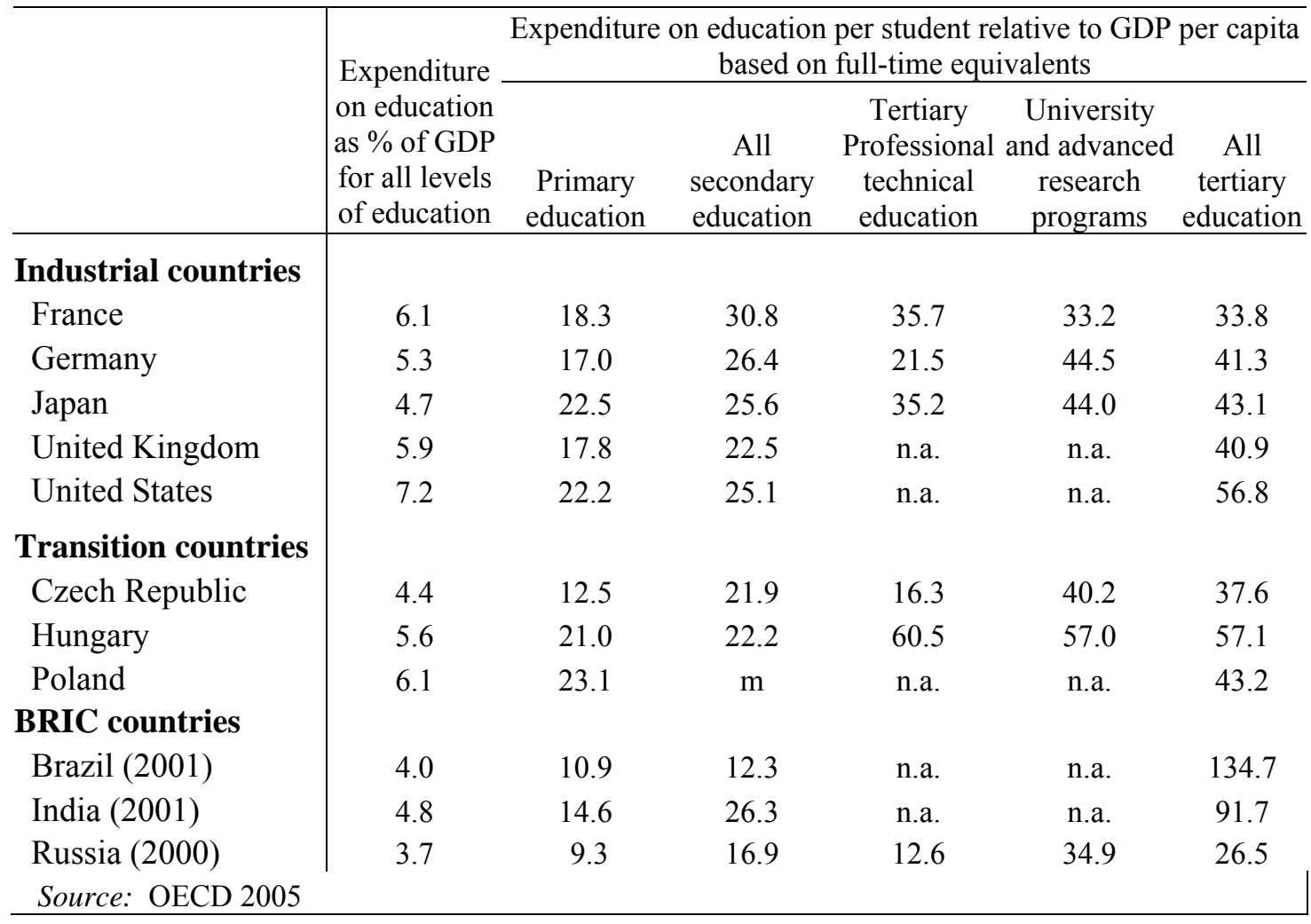

Looking at annual expenditures per student relative to GDP per capita, Russian funding for education is skewed towards tertiary education. For secondary education, this ratio is 9.3 percent, comparable in levels to spending in Indonesia, Uruguay and Peru. For 
university-level education, the ratio is 34.9 percent which is comparable to that of France but behind Germany and Japan.

In contrast, the ratio of students to teaching staff in Russian educational and training institutions is low internationally. In primary schools, the ratio is 17 pupils per teacher and is close to values typical for most of the developed and transition countries; in secondary schools, the ratio is the lowest in the world with 8.5 pupils per teacher; in universities, it is 15 which is also lower than in most developed or transition economies. Low student-teacher ratios in the face of severe under-funding at lower levels of education can be explained by very low pay in the educational sector. In 2004, average monthly wage in the education sector was only 62 percent of the average wage in the economy as a whole, and 53 percent of the average wage in industry (not controlling for individual characteristics). The likely consequences of low relative pay are negative selection of faculty into the education sector, diminished incentives, and a lower quality of instruction.

Russia's performance in internationally comparable standardized tests lends some support for this conclusion. According to TIMSS (Trends in International Mathematics and Science Study), which is administered to $4^{\text {th }}$ and $8^{\text {th }}$ grade students, Russian students in 2003 had achievement scores in mathematics and science at the $4^{\text {th }}$ grade level that were above the international average, placing Russia at the $10^{\text {th }}$ and $11^{\text {th }}$ place among 28 countries that participated. However, Russia lagged behind the leaders - Singapore, Hong Kong and Taiwan - at this $4^{\text {th }}$ grade level. Russia continues to perform well at the $8^{\text {th }}$ grade level for student achievement in TIMMS, scoring above the international average for the 50 participating countries but now slipping to $14^{\text {th }}$ and $21^{\text {st }}$ place internationally (see Table 2).

Table 2. Russian Student Achievement Scores in TIMMS and PISA

\begin{tabular}{|c|c|c|c|c|c|}
\hline TIMMS, 8 grade & 1995 & 1999 & 2003 & $\begin{array}{c}\text { International } \\
\text { mean score }\end{array}$ & $\begin{array}{l}\text { International } \\
\text { ranking }\end{array}$ \\
\hline Mathematics & 524 & 526 & 508 & 467 & 14 out of 50 \\
\hline Science & 523 & 529 & 514 & 474 & 21 out of 50 \\
\hline PISA, 15 years old & & 2000 & 2003 & & \\
\hline Literacy & & 462 & 442 & 480 & 32 out of 40 \\
\hline Mathematics & & 478 & 468 & 486 & 29 out of 40 \\
\hline Science & & 460 & 489 & 488 & 24 out of 40 \\
\hline Problem solving & & - & 479 & 486 & 28 out of 40 \\
\hline
\end{tabular}

On PISA (Programme for International Student Assessment), which asseses the quality of education for 15 year old students, Russia in 2003 had average literacy scores of 442, markedly below the international average score of 480 . This put Russia in $32^{\text {nd }}$ place among the 40 countries participating, and some 90-100 points behind the scores received by the leaders - Finland, the Republic of Korea and Canada. Russia's scores on student assessments in mathematics, science and problem solving were similarly low, and below 
the international average. One explanation for lower scores on PISA is the test's focus (unlike TIMMS) on applied knowledge, which is consistent with the observation that Russian schools tend to place greater emphasis on acquisition of encylopedic knowledge over problem solving, innovative thinking and creativity (that is, the constructive use of knowledge as opposed to its mere accumulation). ${ }^{4}$

The inference to be drawn from these test scores is that the quality of lower secondary education in Russia is poor, relative to that in other developed and almost all other transition countries, and that many students enter the labor market poorly equiped for the demands of the work place. Furthermore, comparing Russia's test scores on TIMMS and PISA for several years in Table 2, it is clear that quality has also deteriorated over time.

\section{Box 1. Reforms to Vocational Education in Russia}

The need for reform of the vocational education system in Russia is probably greater than for either secondary or higher education. The inheritance of a supply-driven, tightly controlled and micromanaged system designed to fit into a planned economy has proved very difficult to reshape to fit Russia's current needs, not least because of stakeholders' resistance to change. With the demise of the majority of SOEs and of the traditional settings in which vocational education has operated in the past, gaps between labor market trends and the qualifications and training provided by vocational education has widened. This growing mismatch has occurred at the very time rapid technological development and global competition requires a more flexible, learning-ready, and skilled workforce.

Key issues for reform include (i) governance, where a large numbers of agencies oversee the VET system; (ii) rigid professional standards, which slow adoption of a competency-based qualification system; (iii) lack of emphasis on core transferable skills, instead of narrowly defined skills; (iv) inadequate funding to finance operations, upgrading of VET infrastructure and instructor skills; and (v) consolidation of the fragmented VET system.

Source: Mary Canning (2005), “The Modernization of Education in Russia”, World Bank.

How about higher levels of education? The IALS (International Adult Literacy Survey) assesses how well equipped adults of different levels of education are for the demands of the workplace, including the ability to apply knowledge to real-world situations - a core competency that is highly valued by most employers throughout the world. Russia has not participated in IALS so no internationally comparable assessments can be made of how well Russian schools prepare students for the world of work, especially at the higher levels of education not covered by TIMMS or PISA - including upper secondary, and vocational, professional and technical institutes below the university level. If funding is any indication, the quality and work-place relevance of the education and training provided by these institutions are also likely to be low, given Russia's under-funding (by international standards) of these institutions (see Table 1). While reforms have taken place or are taking place in some regions, many vocational, professional and technical

\footnotetext{
${ }^{4}$ See David Fretwell and Anthony Wheeler (2001), "Russia Secondary Education and Training”, World Bank Secondary Education Series.
} 
institutions continue to operate along pre-transition supply-driven lines, providing without input from employers narrowly specialized skills which do not meet emerging market needs (see Box 1).

\section{Restructuring and human capital accumulation}

High rates of educational attainment are not simply a legacy from the pre-transition period. While demand for higher education fell in the immediate post-reform period, enrollments rose again in the mid-1990s and today they exceed the enrollment rates prevailing in the late 1980 s.

Table 3 presents the educational distributions of the population age 15 years and older from the 1989 and 2002 censuses. Over this period, the proportion of persons with university-level education (complete and incomplete) increased by 6 percent points while that of tertiary-level (SSUZ) professional and technical education rose 8 percentage points. The shares of persons with primary vocational and general secondary education remained unchanged. At the lower end of the education scale, the share of those with lower secondary education decreased by 3.5 percent points while those with primary or less than primary fell by 4 and 5.5 percentage points, respectively. These shifts are even more pronounced if only the employed workforce is considered. The 2002 General Census suggests that now almost 60 percent of workers have some tertiary education, while the share of low-educated workers (lower secondary or less) has now fallen to below 7 percent.

Table 3. Schooling Completion Rates in Russia, 1989 and 2002

\begin{tabular}{l|rrrr}
\hline \multirow{2}{*}{$\begin{array}{l}\text { Highest level of schooling } \\
\text { attained }\end{array}$} & \multicolumn{2}{c}{$\begin{array}{c}\text { Total Population Aged } \\
\text { years and older }\end{array}$} & \multicolumn{2}{c}{$\begin{array}{c}\text { Employed Population } \\
\text { Aged 15 years and older }\end{array}$} \\
\cline { 2 - 5 } & 1989 & 2002 & 1989 & 2002 \\
\hline Higher complete & 11.3 & 16.2 & 14.6 & 23.3 \\
Higher incomplete & 1.7 & 3.1 & 1.3 & 3.0 \\
Tertiary (SSUZ) & 19.2 & 27.5 & 24.3 & 35.7 \\
Secondary vocational & 13.0 & 12.8 & 17.8 & 15.3 \\
Upper secondary general & 17.9 & 17.7 & 20.8 & 16.2 \\
Lower secondary general & 17.5 & 13.9 & 13.5 & 5.6 \\
Primary & 12.9 & 7.8 & 6.7 & 0.9 \\
Preprimary & 6.5 & 1.0 & 1.1 & 0.1 \\
Total & 100 & 100 & 100 & 100 \\
\hline
\end{tabular}

Source: Rossstat, various years.

How much of the increase in educational attainment of the workforce was the result of changes in the industrial and occupational composition of employment that accompanied restructuring, and how much to education upgrading within industries and occupations? A decomposition of the effects of industrial and occupational changes, ${ }^{5}$ done separately for 1992 to 1996 and for 1997 to 2002, suggests the following results:

${ }^{5}$ A shift-share approach is used to decompose changes over time in educational attainment attributable to different components - one that measures the results of shifts in the industry and occupational composition of employment, holding education constant; another that measures the contribution of rising education, 
- In both periods, the largest contribution to rising educational attainment of the workforce came from educational upgrading within industries and occupations rather than their reallocation across industries and occupations.

- In the initial 1992-1996 period, about a quarter of all improvements in educational attainment was associated with shifts between industries, with inter-industry shifts having a slightly positive effect on demand for workers with higher education, and stronger effects for those with secondary education and tertiary-level professional and technical training. Inter-occupation shifts contributed 18.5 percent, and favored the least educated group of workers.

- In the more recent 1997-2002 period, virtually all the rising educational attainment came from educational upgrading within industries and occupations. The contribution of shifts across industries decreased to 2.6 percent, while that of inter-occupational shifts nearly halved to 10.6 percent.

This decomposition highlights the fact that while changes in the structure of industry and occupations contributed modestly to educational upgrading of the workforce in the early 1990 s, most of the subsequent educational upgrading proceeded independently of restructuring. That this educational upgrading took place across the board, and within all industries and occupations, suggests the presence of a strong skill-biased change process, in technological change and in the transformation of organizational and institutional arrangements in the workplace. The demand for education is likely to increase in such an environment of change, given the comparative advantage that educated workers have in implementing new technology or more generally in responding to disequilibria. ${ }^{6}$

\section{Returns to Education}

The rising returns to education in Russia help explain why demand for education was so strong over the transition period. Rates of return, estimated based on Mincer-type wage equations, suggest that private returns to an extra year of schooling prior to the transition were in the range of 2 to 3 percent, reflecting wage compression resulting from the administratively-set 'wage grid' system. The demise of centralized wage-setting led to a rapid increase in the education premium - returns to an extra year of education rose to about 7 to 8 percent in the first five years of transition, and then by an additional 2 to 3 percent in the later period, stabilizing at 8 to 10 percent by 2000-2002 (see Figure 2).

Similar patterns of post-reform rising returns to education can be observed in other former socialist countries. Table 4 reports returns to education estimated by Fleisher,

holding industry and occupation mix constant; and a third inter-action term. The 1992-1997 decomposition uses 6 education, 50 occupations and 15 industry groups, while the 1997-2002 decomposition relies on 7 education, 32 occupations and 19 industrial groups.

${ }^{6}$ See Theodore Schultz (1975), "The value of the ability to deal with disequilibria"; Anne Bartel and Frank Lichtenberg (1983), "The comparative advantage of educated workers in implementing new technology", and Tan (2005), "The skills challenge of new technology". 
Sabirinova and Wang (2004) for several transition countries, separately for 3 periods: pre-reform, early reform and late reform. Rates of return to education almost doubled between the pre-reform and late reform period for many CIS countries, while those in Russia more than doubled. For China, increases in the returns to schooling were even more dramatic. Because it had much lower pre-reform rates of return of about 1.5 percent, returns to schooling had quadrupled by the late reform period.

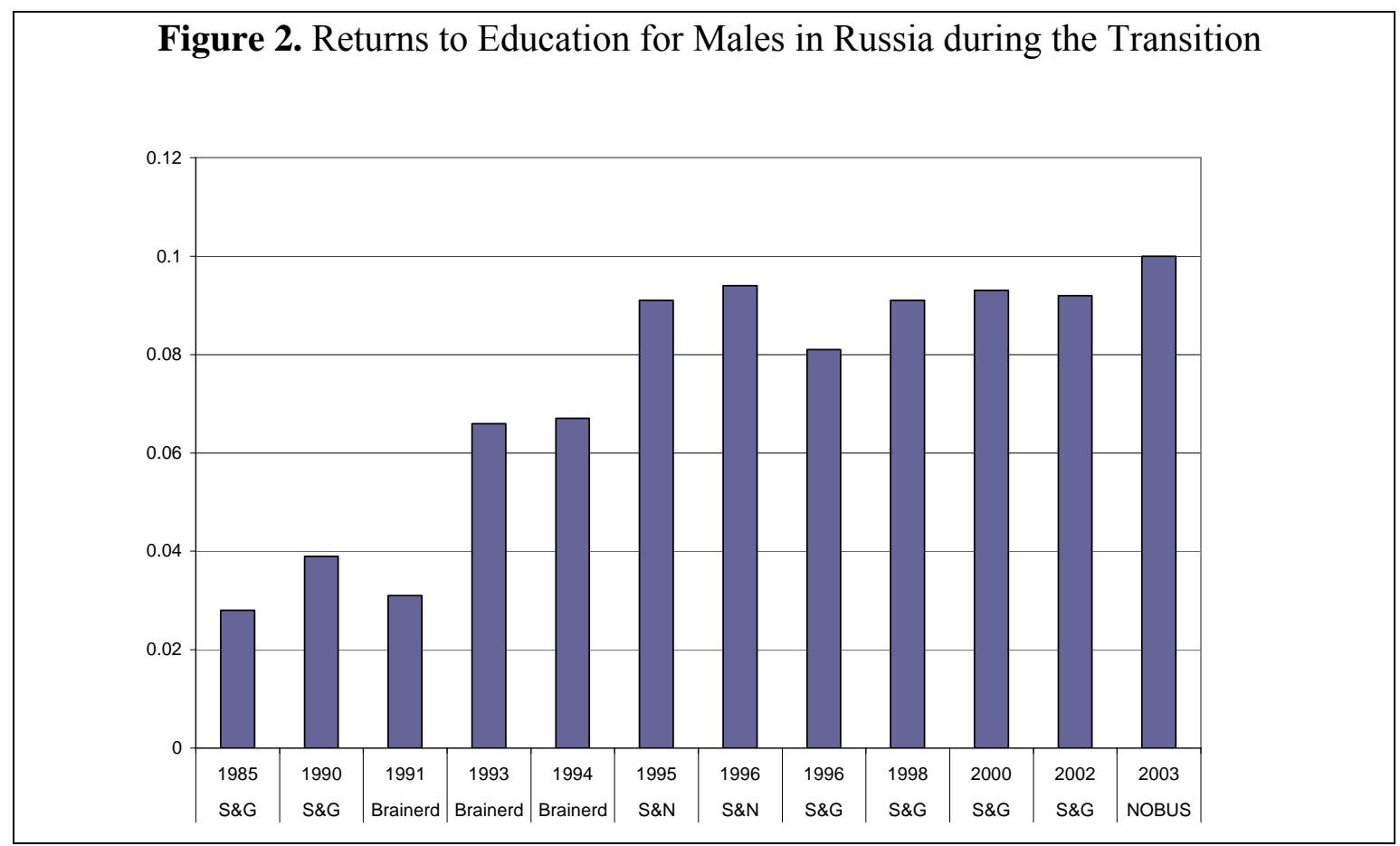

Source: Pop-Eleches, Gimpelson, and Tesluk (2005)

Table 4. Rates of Return to Schooling in Transition Countries

\begin{tabular}{|l|c|c|c|c|}
\hline Country & $\begin{array}{c}\text { Reform } \\
\text { Starting } \\
\text { Point }\end{array}$ & $\begin{array}{c}\text { Pre-reform } \\
\text { Period }\end{array}$ & $\begin{array}{c}\text { Early } \\
\text { Reform } \\
\text { Period }\end{array}$ & $\begin{array}{c}\text { Late Reform } \\
\text { Period }\end{array}$ \\
\hline China & 1979 & 0.015 & 0.025 & 0.061 \\
Czech Republic & 1991 & 0.039 & 0.070 & 0.083 \\
Estonia & 1992 & 0.025 & 0.076 & $\mathrm{Na}$ \\
Hungary & 1990 & 0.067 & 0.074 & 0.098 \\
Poland & 1990 & 0.046 & 0.067 & 0.072 \\
Romania & 1992 & na & 0.046 & 0.056 \\
Russia & 1992 & 0.039 & 0.075 & 0.092 \\
Slovak Republic & 1991 & 0.038 & 0.061 & 0.097 \\
Slovenia & 1991 & 0.043 & 0.063 & 0.070 \\
Ukraine & 1992 & 0.040 & na & 0.055 \\
\hline
\end{tabular}

Source: Fleisher, Sabirianova, and Wang (2004)

This phenomenon of rising returns to schooling is not unique to transition economies. Rates of return to schooling have risen in many countries, in Brazil over the past two decades and in India this past decade as the two countries liberalized their economies and 
became increasingly integrated into global markets. ${ }^{7}$ In these countries, as in the transition economies, economic change brought about by opening up economies to global trade or moving from a centrally-planned to a market economy created strong demand for (and rising returns to) more educated and skilled workers.

Figure 3. Returns to Education by Level of Schooling Attainment

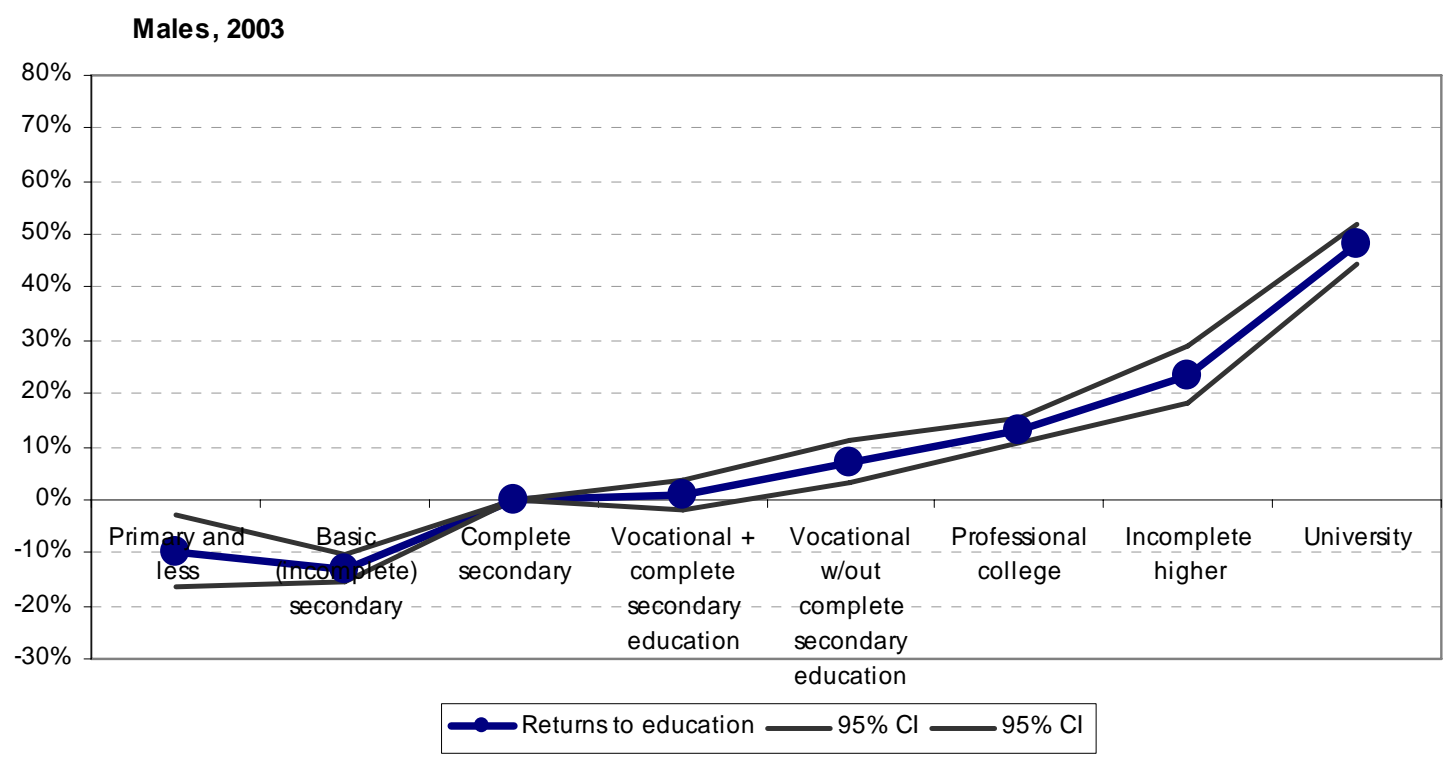

Females, 2003

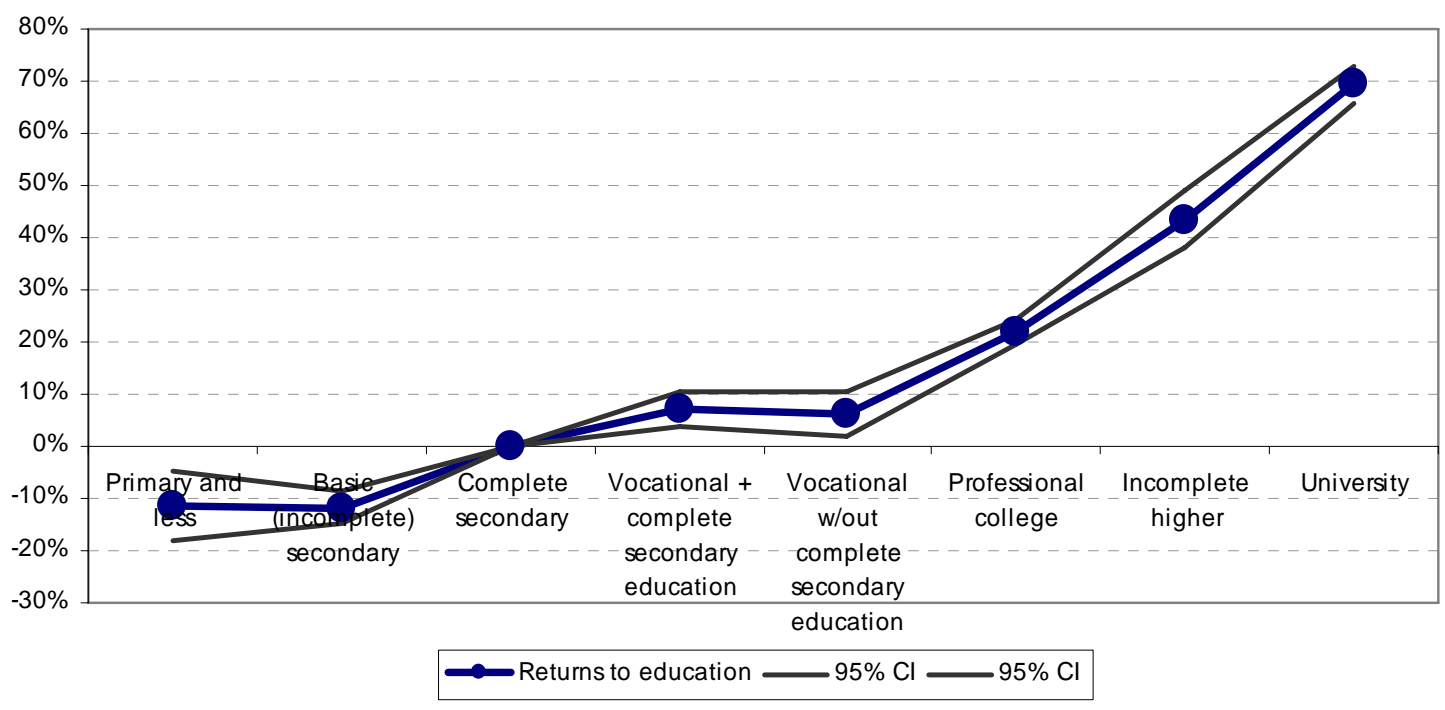

Source: NOBUS, 2003

When returns are differentiated by level of education, specialized training tends to yield lower payoffs than obtaining more general education. Figure 3 shows, separately for

\footnotetext{
${ }^{7}$ For example, see Blom, Holm-Nielsen and Verner, "Education, Earnings and Inequality in Brazil: 19821998", World Bank, and Riboud, Tan and Savchenko (2006), "Globalization and Education and Training in South Asia", forthcoming.
} 
males and females, the wage increments to each level of education in excess of complete secondary education. Getting vocational training increases wages of secondary school graduates by about 5 percent; tertiary-level professional and technical colleges (SSUZ) which provide training in specific skills areas yield wage increases of 13 percent for males and 20 percent for females. University educated males earn 50 percent more than those who complete secondary school, while the wage premium for females is about 70 percent. These high returns to university-level education explain why enrollment rates in higher education have risen over the transition. And the fact that schooling returns have stayed high despite the increasing supply of educated workers indicates that the demand for higher education is very strong, and exceeds supply.

\section{Micro Evidence on Skills Constraints and Labor Shortages}

The previous section highlighted several macro skills trends - an increased supply of educated workers, concerns about quality and possible deterioration in the quality and relevance of education and training received; and strong demand for education in excess of available supply as reflected in continued high returns to schooling in the face of rising school enrollments. Against that backdrop, this section turns to micro evidence from firm surveys, including the Russia Competitiveness and Investment Climate Survey, to gain insights into the increasing frequency of employer complaints about labor and skills shortages, whether these concerns are justified, which firms are most affected by skills shortages, and what factors if any constrain enterprises from responding to these perceived skills shortages.

\section{Firms’ Perceptions of Labor and Skills Shortages}

Respondents to the Russia ICS ranked "Lack of skilled and qualified workforce" as the number 2 investment climate constraint to enterprise growth and development (number 1 constraint being taxation). Small enterprises with less than a 100 employees (the SE sample) also ranked this skills constraint as major or severe, though not as highly as regulation or access and cost of finance (see Figure 4$)^{8}{ }^{8}$

This skills constraint is not new, but has been growing over time with the transition from a planned to a market economy and with rapid economic growth since the late 1990s. Time series data from the quarterly Russia Economic Barometer (REB) surveys provide insights into how over- or under-staffing in enterprises has changed over the last two decades. Prior to the 1998 financial crisis, the proportion of firms reporting that they were over-staffed relative to expected output over the coming year was high - in 1997, 38 percent of firms noted that they had redundant personnel. The strong recovery in industrial output that started after 1998 brought the proportion of overstaffed firms down to the level of under 15 percent (see Figure 5).

\footnotetext{
${ }^{8}$ In addition to ranking each constraint on a scale of 1 to 5 , with 5 being a severe constraint, enterprises in the LME and SE surveys were also asked to identify the most severe constraint from among the previous list. This alternative ranking yielded broadly similar findings, with lack of a qualified workforce being ranked number 3 by medium and large enterprises and number 2 by small enterprises.
} 
Figure 4. Proportion of Enterprise Ranking Workforce Skills As Major or Severe Investment Climate Constraints

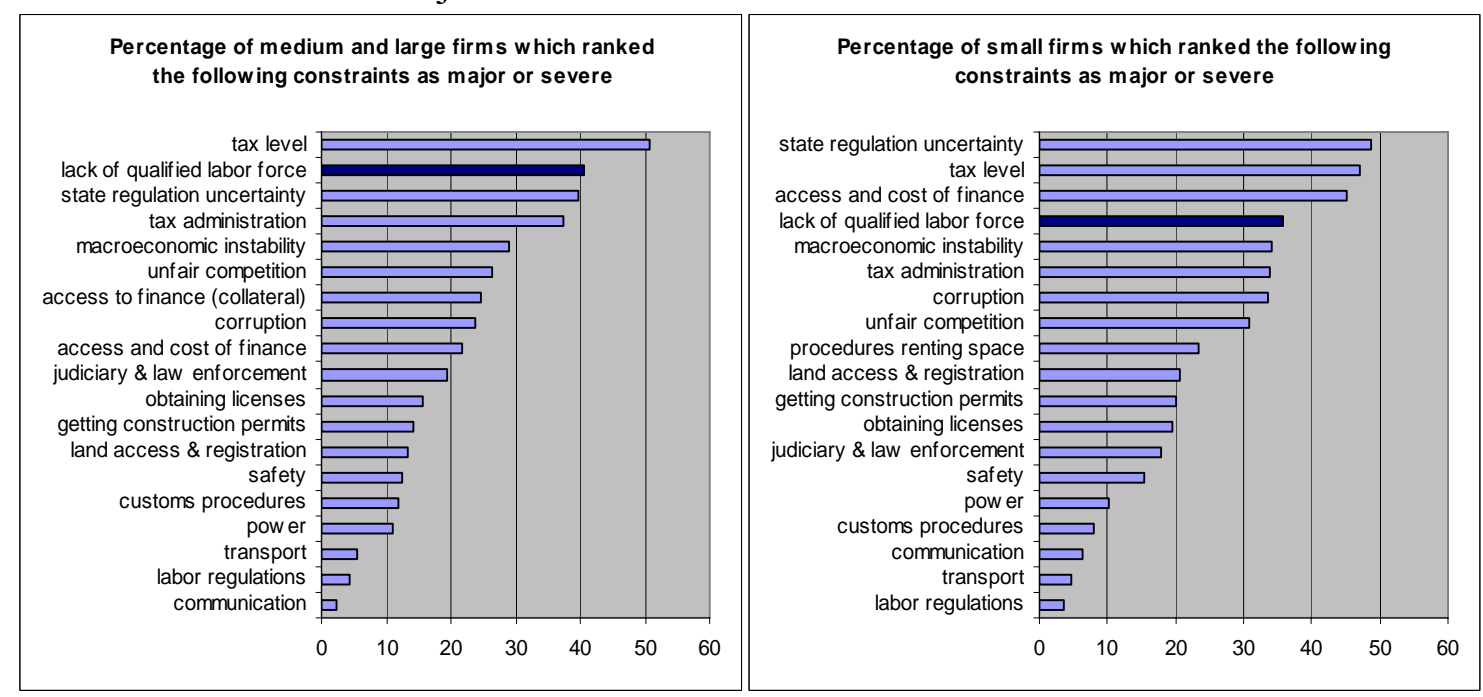

Source: Russia LME and SE Surveys, 2005.

Figure 5. Over- and Under-Staffing in Russian Enterprises

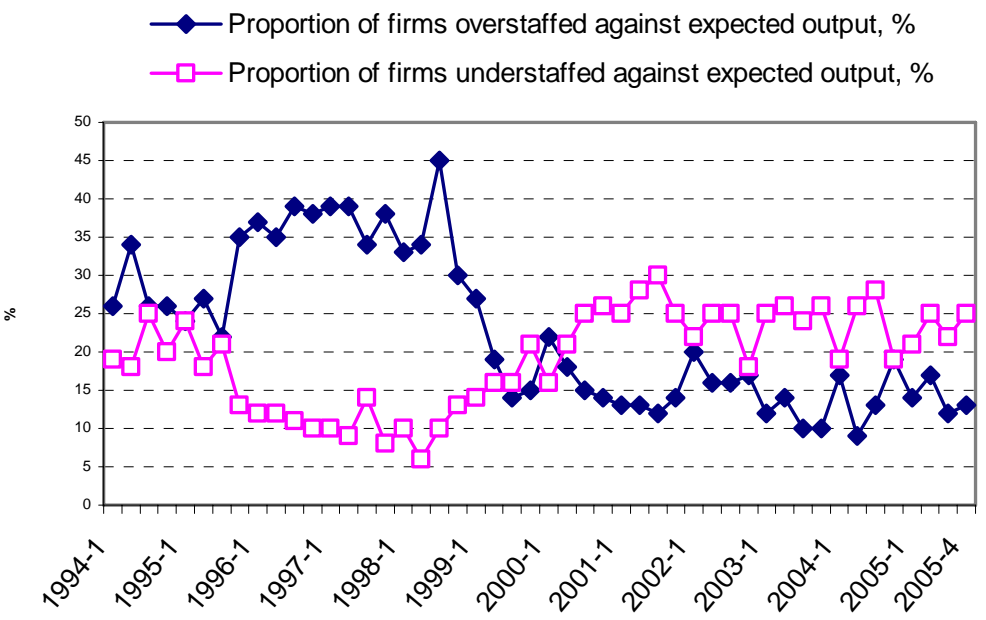

Source: REB

Meanwhile, the problem of understaffing began to emerge. The proportion of firms reporting that existing personnel was not sufficient to meet expected demand started to grow after 1998, and by 2004, almost every fourth firm reported under-staffing against expected output. The shift from overstaffing to labor shortage is consistent with labor utilization rates - that grew from around 70 percent in the mid-1990s to 90 percent in 2005 , indicating almost full utilization of the workforce - and with the 1.5 times increase in output over the 1999-2005 period against a slight decrease in employment in the corporate sector. 
In the 2005 Russia ICS, about 60 percent of surveyed managers rated their current staffing levels as "optimal" relative to current output. Of the remaining enterprises, 27 percent felt that they were "under-staffed" and 13 percent as "over-staffed". On average, under-staffed firms were short by 17 percent of personnel while over-staffed firms had 15 percent more workers than they currently needed. This means that a sizeable fraction of Russian enterprises had difficulties adjusting the size of their workforce to staffing levels dictated by their current output.

Table 5. Characteristics of Firms by Optimality of Staffing Levels

\begin{tabular}{|c|c|c|c|c|c|}
\hline \multirow{2}{*}{ Firm Characteristics } & \multirow{2}{*}{$\begin{array}{c}\text { Optimal } \\
\text { Staffing } \\
\% \text { of firms }\end{array}$} & \multicolumn{2}{|c|}{ Under-staffed } & \multicolumn{2}{|c|}{ Over-staffed } \\
\hline & & $\begin{array}{l}\% \text { of } \\
\text { firms }\end{array}$ & $\begin{array}{c}\text { by what } \\
\text { percentage }\end{array}$ & $\begin{array}{l}\% \text { of } \\
\text { firms }\end{array}$ & $\begin{array}{c}\text { by what } \\
\text { percentage }\end{array}$ \\
\hline \multicolumn{6}{|l|}{ Industry } \\
\hline Metallurgy & 56.5 & 29.4 & 19.5 & 14.1 & 13.5 \\
\hline Chemicals & 52.4 & 25.0 & 8.9 & 22.6 & 13.7 \\
\hline Machinery & 57.1 & 29.6 & 17.9 & 13.3 & 15.3 \\
\hline Wood processing & 60.7 & 25.0 & 11.6 & 14.3 & 11.0 \\
\hline Textiles & 41.9 & 50.5 & 22.6 & 7.5 & 12.3 \\
\hline Food & 74.3 & 15.5 & 13.2 & 10.2 & 16.8 \\
\hline \multicolumn{6}{|l|}{ Firm size } \\
\hline Less than 250 & 62.9 & 29.0 & 22.0 & 8.1 & 13.6 \\
\hline $251-500$ & 58.4 & 28.2 & 15.2 & 13.3 & 16.8 \\
\hline $501-1000$ & 61.4 & 22.8 & 8.6 & 15.8 & 15.0 \\
\hline More than 1000 & 51.1 & 25.2 & 11.7 & 23.8 & 13.2 \\
\hline \multicolumn{6}{|l|}{ Exporter } \\
\hline No & 62.2 & 27.6 & 20.0 & 10.2 & 14.4 \\
\hline Yes & 56.9 & 26.9 & 13.4 & 16.2 & 14.7 \\
\hline \multicolumn{6}{|l|}{$R \& D$ spending } \\
\hline No & 63.6 & 26.8 & 16.9 & 9.6 & 14.4 \\
\hline Yes & 56.3 & 27.7 & 17.1 & 16.0 & 14.7 \\
\hline \multicolumn{6}{|l|}{ New firm (after 1992) } \\
\hline No & 60.0 & 26.5 & 16.5 & 13.6 & 14.6 \\
\hline Yes & 59.1 & 30.2 & 18.6 & 10.7 & 14.8 \\
\hline \multicolumn{6}{|l|}{ Foreign ownership } \\
\hline No & 61.8 & 26.8 & 16.9 & 11.5 & 14.3 \\
\hline Yes & 53.3 & 29.0 & 17.3 & 17.8 & 15.3 \\
\hline \multicolumn{6}{|l|}{ Government Control } \\
\hline No & 61.0 & 26.7 & 14.9 & 12.3 & 14.5 \\
\hline Yes & 56.7 & 28.7 & 21.8 & 14.5 & 14.8 \\
\hline \multicolumn{6}{|l|}{ Competitiveness } \\
\hline High & 60.6 & 24.8 & 11.6 & 14.7 & 15.6 \\
\hline Medium & 61.2 & 26.9 & 15.6 & 11.9 & 14.7 \\
\hline Low & 47.9 & 35.0 & 25.0 & 17.1 & 14.7 \\
\hline
\end{tabular}

Source: Russia LME Survey, 2005

Table 5 reports the distribution of staffing levels for the Russia ICS sample according to several firm characteristics. The probability and levels of under-staffing are highest for 
firms operating in the textile industry. In this sector, over 50 percent of all surveyed firms reported staffing below the optimal level, with the staffing gap averaging 22.6 percent relative to desired levels. New firms established in or after 1992, small enterprises with less than 250 employees, firms operating in the metallurgy and machine-building sectors, and government-controlled firms (with more than 25 percent public ownership) are also more likely to report understaffing. Over-staffing is more prevalent among large firms (with over 1,000 employees) and firms in the chemicals sector.

Staffing levels are also related to how firms rank their level of competitiveness. Firms rating themselves as having medium to high levels of competitiveness are more likely to report having optimal staffing levels (60-61 percent), and less likely to report either under-staffing (25-27 percent) or over-staffing (12-15 percent). On the other hand, firms that classify themselves as having "low" competitiveness are less likely to have optimal staffing levels (48 percent) and more likely to be under-staffed (35 percent) or overstaffed (17 percent). Whatever the factors that constrain under-staffed firms from employing the personnel they need, or over-staffed firms from discharging redundant staff, non-optimal staffing levels can adversely affect firms' perceptions of their level of competitiveness.

Table 6. Under-Staffing of Different Skills Groups

Classification of Enterprises

Skills \& qualifications of workforce

a major or severe constraint

Yes

No

Overall staffing in the firm is:

Optimal

Under-staffed

Over-staffed

Total

Source: Russia LME Survey, 2005.
Firms report under-staffing in different skills categories

$\begin{array}{ccccc}\text { Managers } & \text { Professionals } & \begin{array}{c}\text { Other white } \\ \text { collar }\end{array} & \begin{array}{c}\text { Skilled } \\ \text { workers }\end{array} & \begin{array}{c}\text { Unskilled } \\ \text { workers }\end{array} \\ 51.1 & 51.8 & 68.4 & 53.8 & 60.3 \\ 40.1 & 38.0 & 40.1 & 25.5 & 38.0\end{array}$

$\begin{array}{lllll}3.0 & 11.8 & 0.7 & 37.0 & 4.9\end{array}$

$\begin{array}{lllll}8.1 & 37.0 & 4.4 & 95.6 & 29.3\end{array}$

$\begin{array}{lllll}3.9 & 14.8 & 2.3 & 42.2 & 6.3\end{array}$

$\begin{array}{llll}4.5 & 19.1 & 1.9 & 53.6\end{array}$

Enterprises are concerned not only with overall staffing levels but also with having the desired skills mix. This is borne out by which firms report under-staffing in several occupational groups - managers, professionals, other white collar employees, skilled workers and unskilled workers. Table 6 shows that firms which rank "skills and qualifications of the workforce" as a major or severe constraint are also more likely to report under-staffing in the different skills groups, as compared to those that do not rank skills constraints highly. The bottom panel of Table 6 cross-classifies under-staffing in different skills groups by whether firms describe themselves as being overall staffed optimally, under-staffed or over-staffed. As might be expected, firms that have less-thanoptimal staffing levels are more likely than other firms to report under-staffing in all skills categories, especially skilled workers ( 95 percent) and professionals ( 37 percent). It is interesting that firms with optimal or more-than-optimal staffing levels also report having skills shortages in the same two skills categories. Specific skills shortages especially of professional and skilled workers can coexist with overall optimal or overstaffing at the level of the enterprise. 
Firms' ranking of skills as a production constraint are supported by the degree of difficulty they experience filling specific skills job vacancies. Table 7 reports the

Table 7. Correlation of skills as a major or severe constraint and the degree of difficulty searching for and hiring different skill groups

Dependent variable:

Probability of skills being

Degree of difficulty searching for and hiring:

$\begin{array}{lc}\text { Managers } & 0.134 * * * \\ \text { Professionals } & 0.234 * * * \\ \text { Other white collar employees } & 0.065 \\ \text { Skilled worker } & 0.443^{* * *} \\ \text { Unskilled worker } & 0.140^{* * *}\end{array}$

Coefficient z-statistic

Source: Russia LME Survey, 2005.

Notes: Coefficients are estimated by probit regression analysis separately for each skill group. correlations between the probability that an enterprise reports skills as a major or severe constraint and its ranking of the difficulty (scale of 1 to 5) in searching for and hiring different skills groups. The correlations are all positive and statistically significant, except for "other white collar employees". They also suggest that enterprise perceptions of skills being a major or severe constraint are driven largely by shortages of skilled workers (correlation of 0.443 ) and of professionals (0.234).

The extent to which skills shortages are a problem varies across units within firms. Figure 6 graphs the percent of firms that ranked several key issues as being a major problem by unit within the firm - operating (or production), economic (marketing, strategy), research and development (R\&D), and human resources. Most firms identified two major problems - lack of technological capacity, and lack of skilled qualified workers - both of which are concentrated in operating units, that is, on production lines. A much smaller fraction of firms reported these as major problems in the economic, research and development (R\&D) or human resources (HR) units.

Figure 6. Major problems by unit within the firm, $\%$ of firms

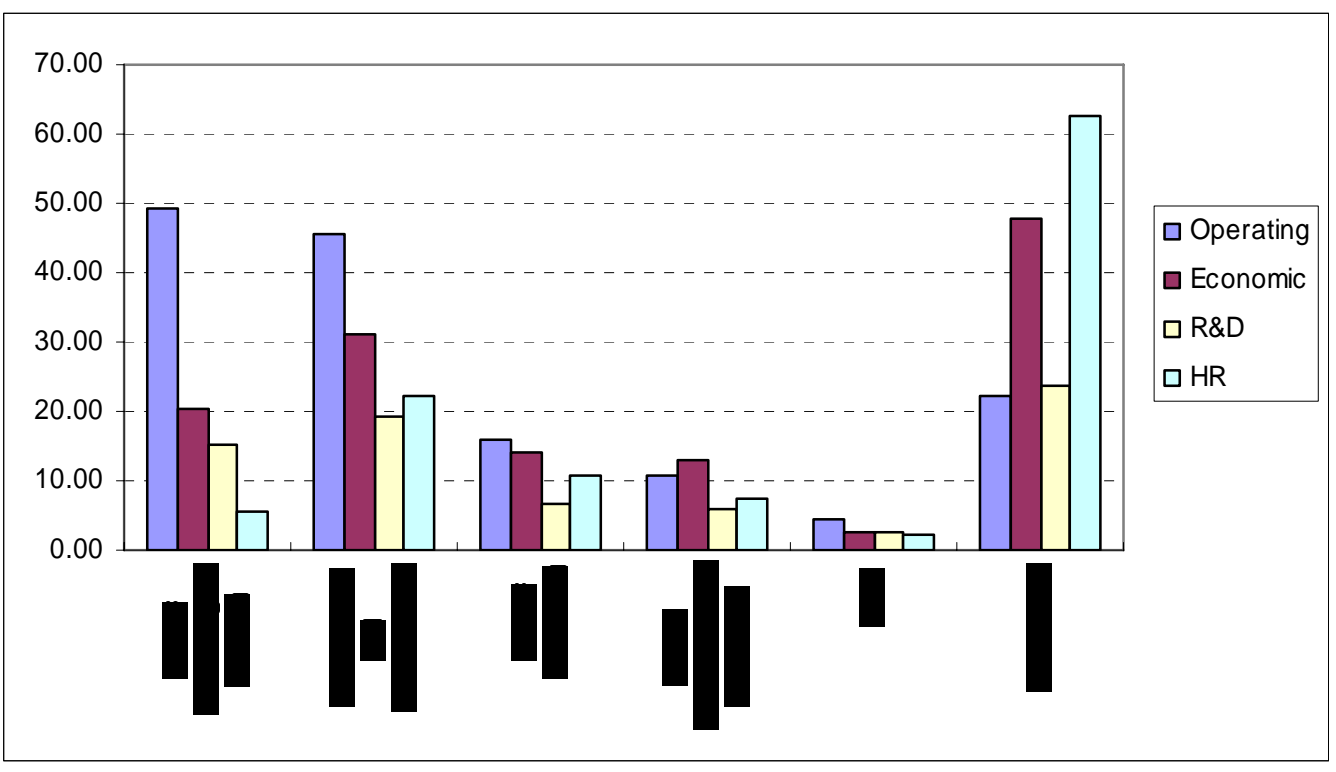


Source: Russia LME Survey, 2005.

Firms experiencing skills shortages tend to cite a number of reasons for under-staffing (see Table 8). The four most commonly listed reasons by frequency of citation are: lack

\begin{tabular}{|l|c|}
\hline \multicolumn{2}{|l|}{ Table 8. Key reasons for under-staffing by } \\
enterprises reporting less than optimal staffing \\
\hline Reasons for Under-Staffing & \% firms \\
\hline High hiring costs & 2.2 \\
\hline $\begin{array}{l}\text { Lack of workers with needed skills in the local } \\
\text { labor market }\end{array}$ & 72.2 \\
\hline High competition for workers in local market & 23.0 \\
\hline Expected decline in demand for output & 4.8 \\
\hline High labor turnover & 30.0 \\
\hline Adverse working conditions & 18.5 \\
\hline Low wages compared to other firms & 41.1 \\
\hline Other reasons & 8.5 \\
\hline $\begin{array}{l}\text { Source: Russia LME Survey, 2005. } \\
\text { Note: Figures do not add to 100 \% because respondents could } \\
\text { select 3 key reasons for under-staffing. }\end{array}$ \\
\hline
\end{tabular}

of workers with needed skills in the local labor market (72 percent), paying low wages compared to other firms (41 percent), high labor turnover (30 percent), and high competition for workers in the local labor market (23 percent). These reasons are consistent with an inadequate supply of workers with relevant job skills in the local labor market (already discussed in Section II), high rates of labor turnover, and payment of non-competitive wages and salaries. These factors are discussed further below, together with the potential role of labor legislation as a constraint on firms' ability to meet desired staff levels and skills mix. In Brazil and India, labor legislation was identified as an important constraint on staffing flexibility (see Box 2). This was not the case in Russia, where most managers did not rank labor legislation highly as a constraint, as compared to their responses regarding skills shortages.

\section{Box 2. Brazilian labor legislation hinders workforce flexibility}

The Brazilian Investment Climate Assessment (ICA) (2006) highlights the significant impacts that rigid labor laws have on the ability of firms to flexibly adjust their workforce and skill mix. 80 percent of firms want to change the size of their workforce. Of the 68 percent that wish to hire more workers, 81 percent report that labor regulations constrain them from doing so, more so than sales growth or union pressure. Regulations restricting firing are particularly onerous for smaller firms, and 68 percent cite labor regulations as a barrier to employment reductions versus 27 percent of large firms. The ICA indicates that firms citing labor laws as a major constraint tend to respond by resorting to hiring informal sector workers under short-term labor contracts. It also finds evidence that rigid labor legislation may affect technology intensive firms disproportionately by making it more difficult for such firms to meet their demand for highly skilled labor.

Source: World Bank (2005), "Brazil Investment Climate Assessment”, Volume II, chapter 6.

\section{Labor turnover and skills shortages}

Labor turnover in Russian firms has been higher than in other former Socialist countries during its transition to a market economy. In 2004, the average rate of new hires was 
about 29 percent, while the job separation rate was 31 percent, giving the Russian economy as a whole a gross labor turnover rate of about 60 percent. These turnover indicators are even higher if only industry is considered, with hiring, separation and gross turnover rates of 30, 35 and 65 percent, respectively (Rossstat, 2006).

Figure 7. Labor Turnover and Skills Mix

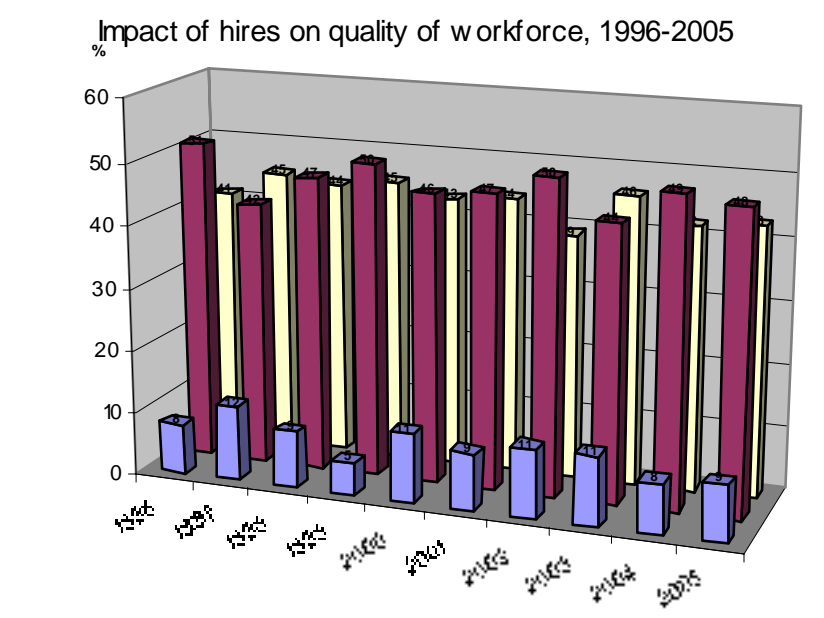

$\square$ Hires have higher skills $\square$ Hires have lower skills

Impact of separations on quality of w orkforce, 1996-2005

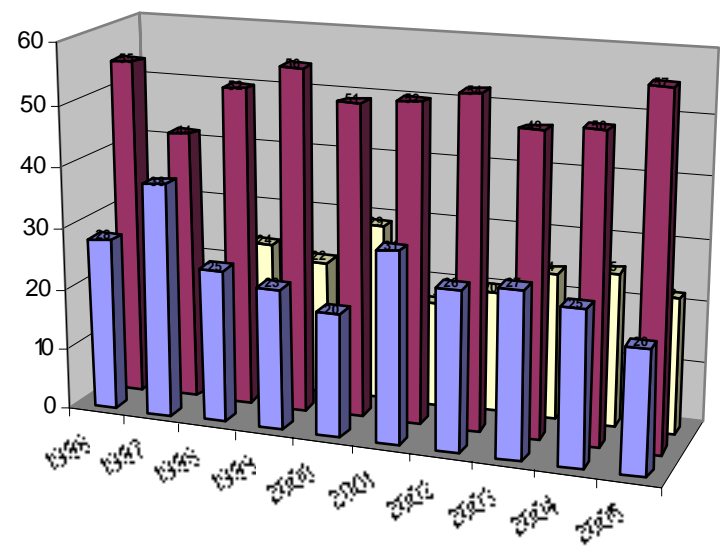

$\square$ Separated have higher skills $\quad \square$ Separated have same skills

$\square$ Separated have lower skills

Source: REB

separations (top panel). The net outcome, at least for one segment of these firms surveyed, is that the overall quality of their workforce fell.
These high rates of labor turnover were not neutral with respect to skills. Managers surveyed in the Russia Economic Barometer (REB) were asked to compare the skills mix of those that were either newly hired or separated to those that remained. Throughout the 1996-2005 period, more than a third of all managers reported deteriorating quality of their work force, about half reported no change in quality, and one tenth reported some improvements in quality due to labor turnover.

Figure 7 suggests that it was the low quality of newly hired workers rather than the high quality of separations that was responsible for the reported deterioration in workforce quality. Almost half of the firms hired workers with lower quality skills (top panel of the figures) while only 10 percent of firms improved workforce quality by hiring more skilled workers. On the other hand, roughly equal proportions of firms improved workforce quality as suffered quality decreases through job one segment of these firms 


\section{Compensation Policies and Skills Shortages}

Respondents to the Russia ICS listed non-competitive wages as one reason for their being under-staffed. If true, non-competitive wages may account for the inability of firms experiencing labor or skills shortages to either retain their skilled workers or to hire equally or more skilled workers from the open labor market, as the REB data noted. Firms may not offer competitive wages if they have below average performance and profitability, that is, are unable to pay high enough wages to retain their most skilled workers or to fill vacant positions with the skilled labor that they need.

There is evidence that under-staffing may be the outcome of low efficiency firms being unable to pay competitive wages. Gimpelson (2004) used data from a survey of 300 large and medium size firms in Russia to investigate whether skills shortages were driven by supply or by demand-side constraints, and if so, what were enterprises doing to respond to reported skills shortfalls. ${ }^{9}$ The analysis suggested that under-staffed firms had levels of labor productivity, profitability and average wages that were lower than those in both optimally-staffed and over-staffed firms. Furthermore, if low efficiency firms (those with low labor productivity, profitability or wages) declared that they had labor or skills shortages, they were more likely to use workers with mass (generic) skills supplied by the traditional vocational education system. In contrast, efficient firms were more likely to search for workers with specific or unique skills whose supply is limited.

Table 9. Staffing Levels and Firm Performance Indicators

\begin{tabular}{|l|c|c|c|c|c|}
\hline Staffing Level & $\begin{array}{c}\text { Value- } \\
\text { added per } \\
\text { worker } \\
\text { (VA/L) }\end{array}$ & $\begin{array}{c}\text { VA/L } \\
\text { relative to } \\
\text { industry } \\
\text { average }\end{array}$ & $\begin{array}{c}\text { Profitability } \\
\text { in } 2004\end{array}$ & $\begin{array}{c}\text { Average } \\
\text { monthly } \\
\text { wages in } \\
2004\end{array}$ & $\begin{array}{c}\text { Employment } \\
\text { growth in } \\
2004\end{array}$ \\
\hline Optimal & 213.5 & 1.05 & 0.11 & 6.246 & -0.53 \\
Under-staffed & 171.4 & 0.88 & 0.08 & 5.620 & -1.05 \\
Over-staffed & 179.8 & 0.90 & 0.10 & 6.295 & -4.06 \\
\hline
\end{tabular}

Source: Russia LME Survey, 2005

A similar pattern of reported staffing levels and firm performance emerges in the 2005 Russia ICS, which includes a much larger sample of industrial enterprises. Table 9 compares firms differing in optimality of staffing by various performance indicators, including value-added per worker, labor productivity relative to the industry average, 2004 profitability, average monthly wage in 2004 , and rate of job creation over the past year. Compared to the other groups, under-staffed firms fare the worst in all these performance indicators. Though under-staffed, they keep losing employment and show negative net employment change over the past year. Over-staffed firms, on the other

\footnotetext{
${ }^{9}$ See Vladimir Gimpelson (2004), "Qualifications and Skill Deficiency in the Labor Market: Lack of Supply, Demand Constraints, or False Signals of Employers?" The survey, conducted jointly by HSE and the Russian Public Opinion Research Center (now Levada-Center), surveyed 304 industrial enterprises located in 30 regions of Russia in 2003, with personnel managers as respondents
} 
hand, are in a slightly better economic shape and show significant (and needed) downsizing over the past year. The best performance in terms of labor productivity and profitability is put in by firms having optimal staffing levels. They pay wages comparable to those paid by over-staffed firms, wages that are significantly above those paid by under-staffed and low productivity firms.

\section{Labor Legislation and Skills Shortages}

Russian enterprises may also be constrained from meeting reported skills shortages by employment protection legislation (henceforth EPL). There is an emerging literature suggesting that overly strict EPL can negatively affect hiring and firing, stifle job creation and lead to higher unemployment. Labor legislation - regarding minimum wages, social benefits and guarantees, employment contracts, and layoff regulations - can change the costs of labor that employers face and, if strictly enforced, inhibit incentives to hire new workers or discharge redundant ones even when warranted by labor demand.

On the World Bank's (Doing Business, 2006) EPL scale, Russia is not among countries with the most stringent EPL. On rigidity of employment, Russia gets a score of 30 which is comparable to China but significantly lower than either Brazil or India (they had scores of 56 and 62, respectively). See Figure 8. Russia's index of employment rigidity is closer to the average for the OECD as a whole, and lower than in most other transition countries (pink bars) except for the Czech Republic, which has a lower score than Russia. According to this source, firing costs in Russia measured in weeks of wages (as compensation for discharge) are also significantly lower than for other BRIC countries (highlighted in darker bars).

Figure 8. Index of Rigidity of Employment Protection Legislation, 2005

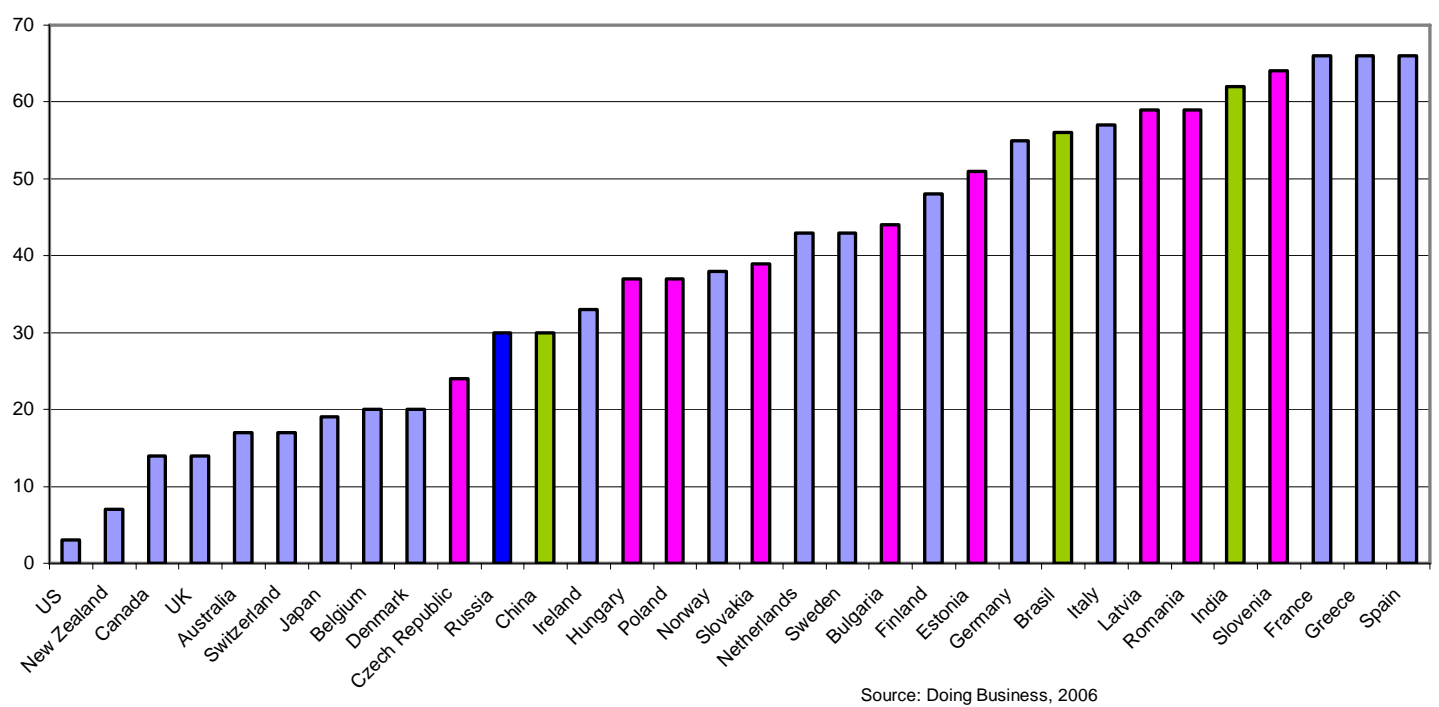

These indices may understate the extent to which EPL in Russia may constrain the staffing decisions of employers. Until 2002, employment in Russia was regulated by the Code of Laws on Labor (KZOT); reforms to the Labor Code in 2001 eliminated many 
contradictory and obsolete requirements, but left the EPL part of the Code relatively unchanged. $^{10}$ The major positive change was in abolishing trade unions' veto power on mass lay-offs. The new code required employers to hire employees on standard openended contracts with full-time working week, and restricted the use of fixed-term employment contracts to specific cases (which stimulated employers to expand use of temporary contracts under these exclusions). In spring 2004, the Supreme Court ruled against the more liberal interpretation of this part of the EPL, and issued directives that fixed-term contracts signed illegitimately must be treated as open-ended.

However, EPL regulations are poorly and selectively enforced, so that their impacts on staffing flexibility may vary across different firms. ${ }^{11}$ The actual "rule of law" is selective and varies across regions, sectors, old and new firms, and also across various segments of the EPL. ${ }^{12}$ In large and mostly unionized firms (accounting for roughly two-thirds of total employment in Russia), the EPL is more strictly enforced while they are barely binding in small firms. Instead of reducing uncertainty, the EPL (through nonenforcement) increases it and differentiates firms according to their mandatory labor costs. Firms that enjoy discretion in applying the EPL may avoid paying severance pay to its workers. Other firms that abide by the rules - typically large and medium size firms - avoid creating new jobs and keep a low wage policy, and many rely on small firms as flexible suppliers of labor (see Box 3).

Figure 9. Which labor regulations create major problems for the enterprise? $\%$ of firms

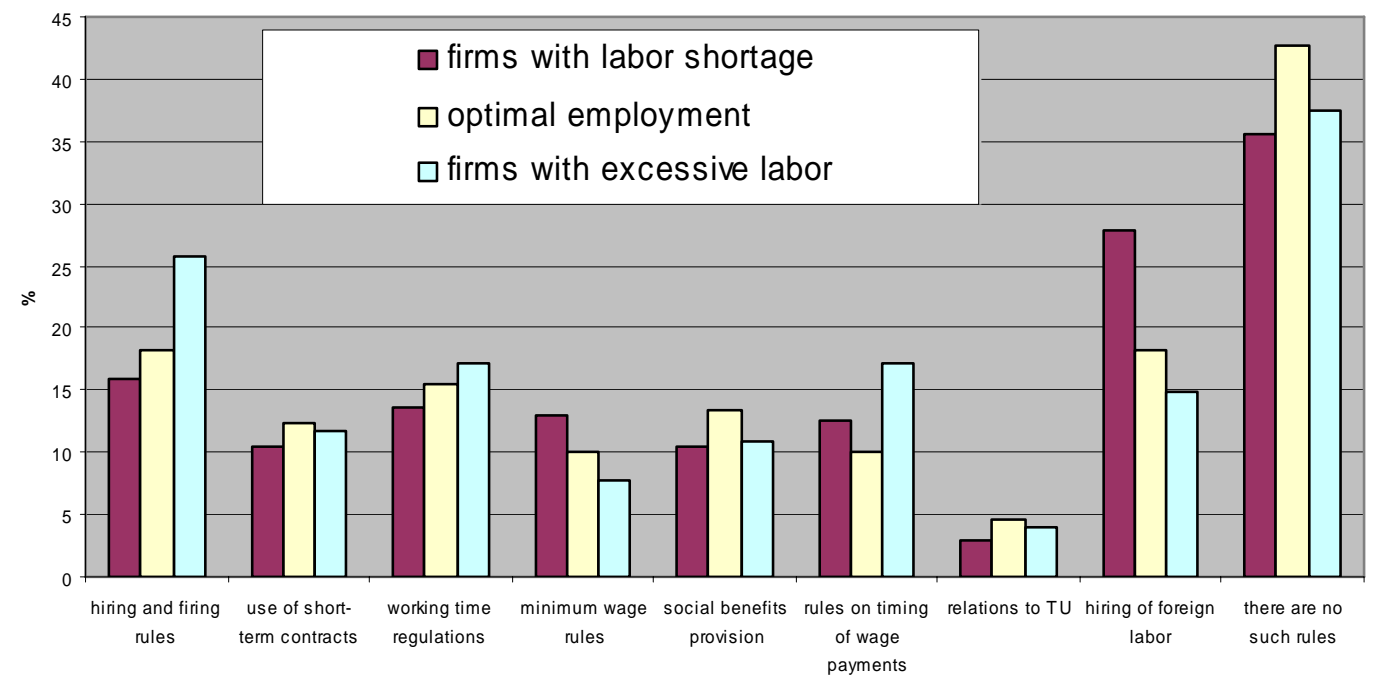

Source: Russia LME Survey, 2005

\footnotetext{
${ }^{10}$ The Russian Labor Code, originally adopted in 1971, was in force throughout the 1990s though with multiple partial amendments. Having been born within the central planning system, it had little to do with the market economy. Under the law, trade unions enjoyed veto power over layoffs and even if they did not object, the costs to employers of discharging redundant personnel were high. In addition, employers were required under this legislation to fund a variety of social benefits and guarantees for employees.

${ }^{11}$ In a recent World Bank study, Rutkovsky and Scarpetta (2005) argue that despite strict EPLs, flexible enforcement of stringent EPL rules provide CIS countries with considerable labor market flexibility.

${ }^{12}$ For example, regulations pertaining to layoffs are enforced better than regulations on overtime work.
} 
Not surprisingly, managers in the Russia ICS do not rank EPL highly as a production constraint as compared to the shortage of skilled labor. ${ }^{13}$ Nevertheless, about 17 percent of respondents ranked it as a notable constraint. In a separate question on labor regulations, only 40 percent of respondents believed that labor regulations do not create major problems for their enterprise (see Figure 9). One fifth reported that rules on hiring foreign labor created serious difficulties, 19 percent pointed to hiring and firing rules and 15 percent stressed the problems of working time regulations. Firms that were overstaffed tended more frequently (than other firms) to select hiring and firing rules, working time regulations, and rules on timing of wage payments as the most constraining among all labor regulations. On the other hand, firms with under-staffing tended to stress minimum wage rules, and rules governing the hiring of foreign workers as creating problems for them. Finally, though the use of short-term contracts is restricted by labor law, 38 percent of surveyed firms reported using them to cover about 10 percent of their workforce.

\section{Box 3. Improving the Labor Code in Russia}

The weak enforcement of the Labor Code has not been a major factor in preventing labor deployment in Russia during the transition. However, there have been trade-offs in promoting informalization of the labor market (through its avoidance), lower worker productivity, and reduced worker welfare (for example, low wages, and growth of in-kind substitutes and wage arrears). What can be done? The enforcement of restrictive law is not the solution. Rather, reducing excessive restrictions and increasing enforcement should be the focus of future efforts. The new Labor Code provides some improvements but more needs to be done, including providing more freedom to employers in deploying their work force as have been provided their counterparts in the OECD.

Areas for consideration include: (i) moving to a flexible labor code that is fully enforced, thereby reducing the distortions and distributional effects created by partial enforcement; (ii) reducing excessive rigidity in the Labor Code, including on work hours and fixed-term contracting; (iii) continuing to increase the minimum wage, which is not adversely binding on employment, but would reduce poverty among low-wage workers; (iv) reducing the influence of tariff in wage-setting: and (v) promoting the development of institutions to allow worker voice, improve work conditions, enforce contracts, and resolve disputes, thereby raising worker productivity.

Source: World Bank (2003), “The Russian Labor Market: Moving from Crisis to Recovery”, a copublication of World Bank and Izdatelstvo Ves Mir.

\footnotetext{
${ }^{13}$ There are simple and quasi-legal ways to deal with EPL constraints and turn labor-management relations into a quasi "employment-at-will" practice. First, employers can pressure workers to quit voluntarily.

Second, there are informal practices of asking workers to submit an application to quit voluntarily at the job application point. This allows managers to date the application and initiate a "voluntary" quit at any moment and at no costs. These (and some other) informal practices can result in high labor turnover driven by quits with almost no lay-offs.
} 
Table 10. EPL as a Constraint on Hiring Skilled Labor

\begin{tabular}{|c|c|c|c|}
\hline \multirow{3}{*}{$\begin{array}{l}\text { Dependent variable: } \\
\text { EPL index }\end{array}$} & \multicolumn{3}{|c|}{ Difficulty in search and hiring of labor } \\
\hline & \multirow{2}{*}{$\frac{\text { Professionals }}{.108}$} & \multicolumn{2}{|c|}{ Skilled workers } \\
\hline & & .094 & - \\
\hline & $(3.03) * * *$ & $(2.66) * * *$ & - \\
\hline \multirow{2}{*}{ EPL is not a constraint } & - & - & -.306 \\
\hline & - & - & $(-3.94) * * *$ \\
\hline \multirow[t]{2}{*}{ Log(wages) } & -.093 & -.199 & -.197 \\
\hline & $(-1.69)^{*}$ & $(-3.66) * * *$ & $(-3.63)^{* * *}$ \\
\hline \multirow[t]{2}{*}{ Government controlled } & .218 & .021 & .023 \\
\hline & $(2.06)^{* *}$ & $(0.20)$ & $(0.21)$ \\
\hline \multirow[t]{2}{*}{ Foreign owned } & -.153 & -.036 & -.042 \\
\hline & $(-1.33)$ & $(-0.32)$ & $(-0.37)$ \\
\hline \multirow[t]{2}{*}{ Small firm ( $<250$ employees $)$} & -.301 & -.166 & -.162 \\
\hline & $(-3.84)^{* * *}$ & $(-2.17)^{* *}$ & $(-2.11) * *$ \\
\hline \multirow[t]{2}{*}{ R\&D spending indicator } & .208 & .044 & .033 \\
\hline & $(2.64) * * *$ & $(0.56)$ & $(0.42)$ \\
\hline \multirow[t]{2}{*}{ New Firm (after 1992) } & .078 & -.115 & -.122 \\
\hline & $(0.83)$ & $(-1.25)$ & $(-1.32)$ \\
\hline Number of observations & 896 & 898 & 898 \\
\hline Likelihood Ratio (chi2) & 123.85 & 181.13 & 189.56 \\
\hline \multicolumn{4}{|c|}{$\begin{array}{ll}\text { Source: } & \text { Russia LME Survey, } 2005 \\
\text { Notes: } & \text { industry and regional control variables included. Z-values in parentheses and * statistically } \\
& \text { significant at } 10 \%, * * \text { significant at } 5 \% \text { and } * * * \text { significant at } 1 \% . \\
& \text { EPL index is the sum of rankings for EPL related difficulties. }\end{array}$} \\
\hline
\end{tabular}

Labor adjustment costs induced by the EPL are likely to make it more difficult for firms to search for and hire needed skilled workers. Table 10 reports estimates from an ordered probit model in which the 5 -score index of difficulty (ranking of 1 to 5 where 5 is maximum difficulty) searching for and hiring skilled labor is regressed on an index of EPL as a constraint (sum of different EPL components that respondents indicate as problematic), wage levels in the firm (to test the Gimpelson hypothesis), and different enterprise characteristics that might shape skills demand. The model is estimated separately for professionals and for skilled workers, the two groups in greatest demand. The results provide evidence that the EPL index is positively associated with the actual difficulties firms experience in searching for and hiring professionals and skilled workers. The higher the sum of EPL rankings as a constraint, the more severely firms report search and hiring difficulties for both professionals and skilled workers. Firms able to circumvent EPL, on the other hand, are less likely to rank search and hiring of skilled labor as a problem. The results in Table 10 also confirm the hypothesis that firms paying low non-competitive wages are also more likely to report difficulties in search and hiring of skilled labor. 


\section{In-Service Training in Russian Enterprises}

One possible solution to skills shortages in the local labor market is for employers to train or upgrade the skills of its existing workforce. The hiring versus retraining option is discussed by Lazareva, Denisova, and Tsukhlo (2006), based upon a survey of 1,000 industrial enterprises in 2004. ${ }^{14}$ In their survey, 56 percent of firms noted that retraining of existing workers is the most efficient way to meet skills shortages, 35 percent state that hiring from the external market is preferable, and 25 percent prefer agreements with education and training institutions to provide trained personnel.

This section focuses on the in-service training and skills upgrading practices of Russian manufacturing firms. The Russia ICS Survey asked employers detailed questions about their workforce and training practices: do enterprises provide any formal in-service training, whether training is from in-house or from external sources, what is the duration of training, and number of employees trained in five broad occupation categories? These data, together with information on different enterprise attributes and production, allow us to examine not only which Russian employers provide in-service training to their workforce, how much, who they train, where they get training but also what are the productivity and wage outcomes of such training investments. Subsequently, the section turns to the issue of how training can complement and support the R\&D and innovative activities of enterprises.

\section{Overview of In-Service Training}

Simple tabulations suggest that about 70 percent of manufacturing enterprises in the LME sample provide employees with in-service training. This figure is not comparable to other countries because the LME survey, by design, focuses on medium and large firms with over 100 employees, and larger firms tend on average to train more than small ones. The BEEPS and ICS surveys, by contrast, tend to include a higher proportion of smaller firms. To compare the incidence of training in Russia to that of OECD and selected comparator developing countries, we adopt a common weighting scheme based (arbitrarily) on the size distribution of firms in the India ICS survey. ${ }^{15}$ The weighted incidence of formal in-service training is calculated for the pooled LME and SE samples from Russia, and for 16 other comparator countries: 6 from the OECD, 3 from East Asia, 2 from South Asia, 2 from Latin America, and 3 from Eastern Europe. ${ }^{16}$

Figure 10 shows estimates of training incidence in OECD countries and in four regions, and separately for the 17 countries used to calculate regional averages. The selected

\footnotetext{
${ }^{14}$ Olga Lazareva, Irina Denisova, and Serguey Tsukhlo (2006), "Hiring or Retraining: Russian Firms' Experience", HSE Working paper WP3/2006/11, 2006.

${ }^{15}$ The size distribution of micro ( 15 or fewer workers), small (16-100 workers), medium (101-250 workers) and large firms (over 250 workers) in India is 40, 44, 7 and 8 percent; the corresponding size distribution for the pooled LME and SE surveys in Russia are 12, 16, 29 and 43 percent

${ }^{16}$ The 17 countries clustered by region include Germany, Greece, Ireland, Portugal, South Korea and Spain (OECD), China, Malaysia and Thailand (East Asia), India and Sri Lanka (South Asia), Brazil and Chile (Latin America), Bulgaria, Lithuania, Serbia and Russia (Eastern Europe).
} 
comparator countries in East Asia and Latin America have higher training incidence than the transition economies in Eastern Europe and OECD countries, with South Asia especially far behind. How does training incidence in Russia compare with its BRIC developing country competitors - Brazil, India, and China? Russia, at 58 percent training incidence, trails behind China ( 92 percent) and Brazil (59 percent), but it is way ahead of India (17 percent).

Figure 10. Incidence of Formal In-Service Training: OECD, Regional and Country Means

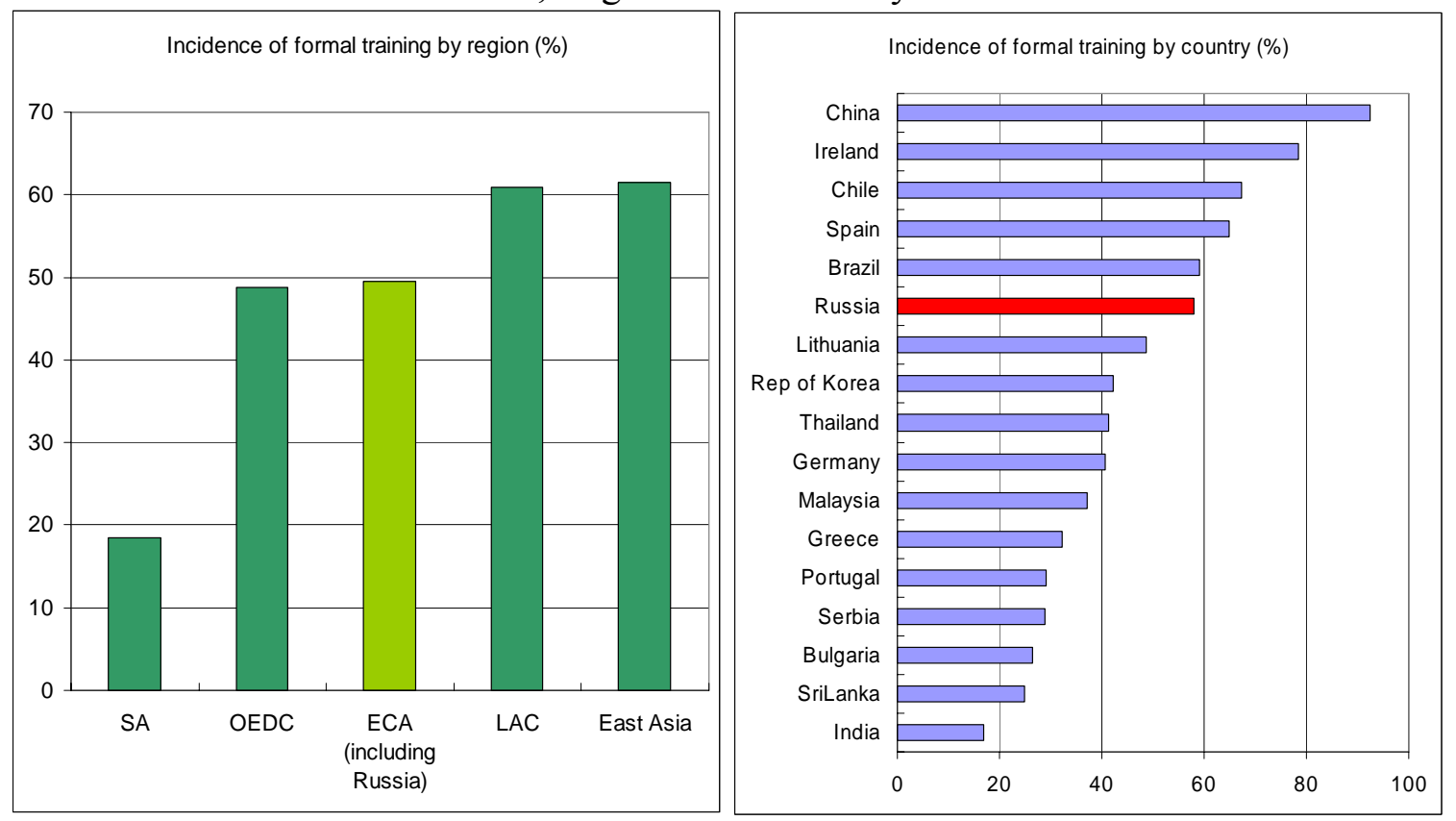

Source: BEEPS, ICS Data base, and pooled Russia LME and SE Surveys

However, these simple training incidence estimates and cross-national comparisons are misleading because Russian firms that train provide training to very few of their employees. The Russia ICS survey elicited data about which skills groups received inservice training and, more importantly, how many were trained. Conditional on the firm providing training, the survey suggests that managers, professionals and skilled workers are the three skills groups most likely to benefit from in-service training, which is consistent with the kinds of skills shortages reported by firms. On average, only 10-11 percent of managers and professionals and about 8 percent of skilled workers receive formal training.

These figures are extremely low internationally, and suggest that in-service training practices are not firmly entrenched among Russian firms. In Malaysia, a fast growing East Asian country that also ranked skills shortages highly ${ }^{17}$, a World Bank study (1997) estimated that 24 percent of managers, 32 percent of professionals and technicians, and

\footnotetext{
${ }^{17}$ In the Malaysian ICS survey, employers ranked the skills and education of the workforce as the number one "severe" or "very severe" investment climate constraint. See World Bank (2004), "Malaysia: Firm Competitiveness, Investment Climate and Growth".
} 
between 13 and 16 percent of production workers received formal in-service training. Thus, while many more Russian firms train, they provide training to a relatively small percent of their workforce as compared to their fast growing counterparts in East Asia.

Table 11 provides cross-nationally comparable estimates of the shares of skilled and unskilled workers receiving formal training ${ }^{18}$, conditional on the enterprise providing in-

Table 11. Share of Workforce Trained

$\begin{array}{lll}\text { Country } & \text { Data Source } & \begin{array}{c}\text { Share of workforce } \\ \text { trained } \\ \text { Skilled }\end{array} \\ & & \end{array}$

$\underline{\text { BRIC }}$

\begin{tabular}{llcc}
\hline Russia & 2005 ICS & $\mathbf{7 . 7}$ & $\mathbf{1 . 4}$ \\
Brazil & 2003 ICS & 52.8 & 45.4 \\
China & 2003 ICS & 44.5 & 28.5 \\
Transition & & & \\
\hline Bulgaria & 2004 ICS & 24.0 & 13.0 \\
Lithuania & 2004 ICS & 11.9 & 4.0 \\
Serbia & 2003 ICS & 45.2 & 6.1 \\
OECD & & & \\
\hline Germany & 2005 BEEPS & 37.3 & 27.2 \\
Greece & 2005 BEEPS & 53.6 & 36.8 \\
Ireland & 2005 BEEPS & 76.0 & 68.1 \\
Portugal & 2005 BEEPS & 75.2 & 50.2 \\
Spain & 2005 BEEPS & 76.1 & 56.2 \\
South Korea & 2005 BEEPS & 65.4 & 59.2 \\
Developing & & & \\
Chile & 2004 ICS & 48.3 & 36.0 \\
Malaysia & 2002 ICS & 69.6 & 52.7 \\
Sri Lanka & 2004 ICS & 47.4 & 34.1
\end{tabular}

Notes: Country samples restricted to manufacturing firms, and shares of workers trained are weighted estimates using the firm size distribution of India. service training. Several groups of countries are represented - BRIC excluding India, transition economies, OECD countries and selected developing countries. Russia stands out among the BRIC group in the very small share of its workforce trained within the firm -7.7 and 1.4 percent of skilled and unskilled workers - as compared to Brazil (53 and 45 percent) and China (44 and 28 percent), both of which also report higher incidence of in-service training than Russia.

The share of Russian workers trained in in-service programs is also lower than in other country groups. It is lower than rates prevailing in several other transition countries (12-45 percent for skilled, 6-13 percent for unskilled workers), in selected developing countries (47-70 percent for skilled, 34-53 percent unskilled), and significantly below OECD countries as a group (typically above 50 percent). It is possible, though unlikely, that these low estimates for Russia are a statistical artifact. ${ }^{19}$ The recent survey of enterprise training practices by Lazareva, Denisova, and Tsukhlo (2006) reports somewhat higher figures - about 20 percent of workers - for Russia that are below those of OECD countries, though it is unclear whether weighting would reduce their estimates of share of workers trained.

\footnotetext{
${ }^{18}$ The sample is restricted to those countries included in the 2005 BEEPS or with Investment Climate Surveys that asked about in-service training and the shares of skilled and unskilled workers that received formal training. Skilled workers are defined to include managers, professionals and skilled production workers, while unskilled workers include unskilled production workers, and other non-production or other white collar employees.

${ }^{19}$ In the Russia ICS, firms reported shares of workers trained in several intervals, including an open-ended "35 percent or more" trained. In calculating shares trained, the mean for this last interval was assumed generously to be 45 percent, possibly biasing up training estimates for Russia. Tabulations of the small sample of Russian firms in BEEPS also reveal low shares of workers trained relative to other countries in the 2005 BEEPS sample.
} 
Which firms train and where do they get their training? Table 12 presents information on the distribution and sources of in-service training, cross-classified by several firm attributes that are hypothesized to shape skills demand (and incentives to train), including employment size, export orientation, positive expenditures on R\&D, foreign ownership,

Table 12. Incidence of formal training by firm characteristics In-house External training training training

\begin{tabular}{|c|c|c|c|}
\hline All firms & 42.81 & 62.37 & 69.60 \\
\hline \multicolumn{4}{|c|}{ SME (<250 workers) } \\
\hline No & 51.41 & 72.71 & 79.12 \\
\hline Yes & 31.08 & 48.33 & 56.67 \\
\hline \multicolumn{4}{|c|}{ Exporter } \\
\hline No & 35.87 & 55.82 & 63.54 \\
\hline Yes & 51.24 & 70.34 & 76.96 \\
\hline \multicolumn{4}{|c|}{ Firm has $R \& D$ spending } \\
\hline no & 34.72 & 55.15 & 62.15 \\
\hline yes & 48.13 & 68.03 & 75.24 \\
\hline \multicolumn{4}{|c|}{ New firm (established on or after 1992) } \\
\hline no & 43.54 & 64.27 & 70.76 \\
\hline yes & 41.31 & 55.19 & 65.42 \\
\hline \multicolumn{4}{|c|}{ Firm has FDI (\% of foreign ownership > =10\%) } \\
\hline no & 43.16 & 64.43 & 71.02 \\
\hline yes & 42.22 & 58.77 & 67.13 \\
\hline \multicolumn{4}{|c|}{ Government controlled ( $25 \%$ or more of shares) } \\
\hline no & 43.03 & 62.23 & 69.77 \\
\hline yes & 42.49 & 62.60 & 69.33 \\
\hline \multicolumn{4}{|c|}{ Investment risk of the region } \\
\hline minimal & 37.91 & 60.71 & 66.34 \\
\hline moderate & 48.27 & 66.67 & 75.50 \\
\hline high & 41.64 & 59.33 & 66.36 \\
\hline
\end{tabular}

Source: Russia LME Survey, 2005 government control and the investment risk of the region.

The simple tabulations suggest that the incidence of in-service training is higher among firms that are larger, are export-oriented and that invest in $\mathrm{R} \& \mathrm{D}$. Long-established firms pre-dating the transition are more likely to provide inservice training than newer firms. Domestically-owned firms tend to train relative to foreign owned firms, and government ownership makes no difference to the likelihood of training. Localities rated as being moderate investment risk regions tend to have higher incidence of training as compared to either minimal risk or high risk regions.

Are firms reporting under-staffing more likely to train to meet skills shortfalls? Surprisingly, the answer to this question is no. In tables and analysis not shown here, reported under-staffing was not correlated with in-service training; neither were employer assessments of occupation-specific under-staffing. In fact, firms that reported themselves as being over-staffed were more likely than firms with optimal staffing or under-staffing to provide in-service training. One explanation, consistent with Table 6, is that skills shortages in specific skills groups can co-exist with overall optimal or over-staffing, so even these firms train. Another explanation is that there are different sources of demand for training, not just for making up numerical labor shortfalls, but also for meeting the specific skills needs of exporting and new technology, as suggested by Table 12 .

So why do Russian firms not train in-house to meet skills shortfalls? Information on why employers might not train or train very little was not elicited in the Russia ICS but is available in the World Business Environment Survey (WBES). WBES asked firms to rank a series of statements about what factors influenced their decisions on how much to invest in training workers. ${ }^{20}$ Figure 11 graphs these WBES rankings separately for firms

${ }^{20}$ The World Business Environment Survey (WBES) was an enterprise survey fielded to more than 10,000 firms in 80 countries between late 1998 and mid-2000. The analyses reported in Batra and Stone (2004) are 
that train (using in-house or external facilities) and for those that do not. Firms that do not train are substantially more likely than firms that do to agree with the following key reasons for not training. First, a majority of firms identified technologies they were using as "mature", and hence did not require training or skills upgrading to use that technology. Second, many cited "lack of affordability of training" because of limited funding, which might suggest a weakness in financial markets. Third, many alluded to the high labor turnover of trained staff, an externality which prevents them from recouping the cost of training. Finally, many employers suggested that informal on-the-job training was adequate or that skilled workers were readily available in the labor market.

Figure 11. Ranking of Reasons for Not Providing In-Service Training

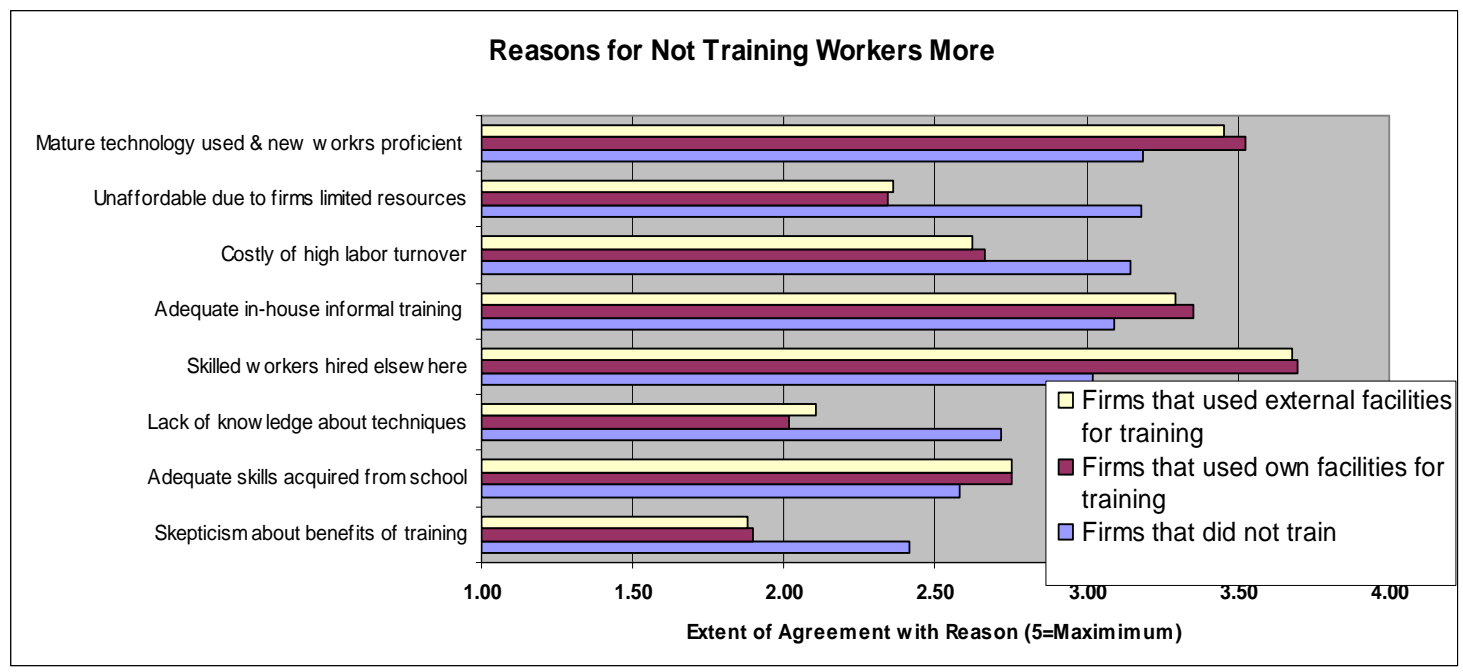

Source: Batra and Stone (2004) using data from World Business Environment Survey.

\section{Determinants of In-Service Training}

The importance of these (and other) training correlates can be investigated within a regression framework using a probit model. ${ }^{21}$ The model estimates the probability of inservice training by regressing the "any formal training" variable on a set of explanatory variables, including measures of firm size, the share of workers with higher education, other firm attributes such as export orientation, R\&D spending, foreign or government ownership, and independent assessments of the regions investment climate risk. A corresponding set of regressions was estimated separately for the probability of in-house training and external training.

based on a special survey module administered in 28 of the WBES countries that focused on issues of competition, trade, and firm capabilities in terms of technology, and worker training.

${ }^{21}$ The advantage of regression analysis over tabular information is that the independent effects of each variable (or set of variables) can be analyzed holding constant the effects of other hypothesized correlates. 
Table 13. Determinants of In-service Training and Training by Source

\begin{tabular}{|c|c|c|c|}
\hline Dependent variable: training $(1,0)$ & Any training & $\begin{array}{l}\text { In-house } \\
\text { training }\end{array}$ & $\begin{array}{l}\text { External } \\
\text { training }\end{array}$ \\
\hline \multicolumn{4}{|l|}{ Firm size dummies } \\
\hline Small size (101-250 workers) & $\begin{array}{l}0.084 \\
(1.42)\end{array}$ & $\begin{array}{l}0.108 \\
(1.41)\end{array}$ & $\begin{array}{l}0.102 \\
(1.56)\end{array}$ \\
\hline Medium size (251-1000 workers) & $\begin{array}{c}0.219 \\
(3.76)^{* * *}\end{array}$ & $\begin{array}{c}0.22 \\
(2.90)^{* * *}\end{array}$ & $\begin{array}{c}0.257 \\
(3.96)^{* * *}\end{array}$ \\
\hline Large size $(>1000)$ & $\begin{array}{c}0.273 \\
(4.86)^{* * *}\end{array}$ & $\begin{array}{c}0.381 \\
(4.58)^{* * *}\end{array}$ & $\begin{array}{c}0.334 \\
(5.24)^{* * *}\end{array}$ \\
\hline$\%$ higher educated workers & $\begin{array}{c}0.003 \\
(2.45)^{* *}\end{array}$ & $\begin{array}{l}0.000 \\
(0.03)\end{array}$ & $\begin{array}{c}0.003 \\
(2.37)^{* *}\end{array}$ \\
\hline New firm (after 1992) & $\begin{array}{l}-0.034 \\
(-0.93)\end{array}$ & $\begin{array}{l}-0.002 \\
(-0.05)\end{array}$ & $\begin{array}{c}-0.068 \\
(-1.72)^{*}\end{array}$ \\
\hline Exporter & $\begin{array}{l}0.055 \\
(1.71)\end{array}$ & $\begin{array}{c}0.065 \\
(1.82)^{*}\end{array}$ & $\begin{array}{c}0.063 \\
(1.81)^{*}\end{array}$ \\
\hline Positive R\&D spending & $\begin{array}{c}0.081 \\
(2.29)^{* *}\end{array}$ & $\begin{array}{c}0.074 \\
(1.91)^{*}\end{array}$ & $\begin{array}{c}0.06 \\
(1.59)\end{array}$ \\
\hline R\&D sales ratio & $\begin{array}{l}1.071 \\
(0.99)\end{array}$ & $\begin{array}{l}0.549 \\
(0.66)\end{array}$ & $\begin{array}{l}0.283 \\
(0.32)\end{array}$ \\
\hline Some foreign ownership (>10\%) & $\begin{array}{l}-0.05 \\
(-1.06)\end{array}$ & $\begin{array}{l}0.037 \\
(0.74)\end{array}$ & $\begin{array}{l}-0.079 \\
(-1.57)\end{array}$ \\
\hline Government control $(>25 \%)$ & $\begin{array}{l}0.059 \\
(1.40)\end{array}$ & $\begin{array}{l}-0.015 \\
(-0.33)\end{array}$ & $\begin{array}{c}0.115 \\
(2.58)^{* *}\end{array}$ \\
\hline IC risk is moderate & $\begin{array}{c}0.097 \\
(2.70)^{* *}\end{array}$ & $\begin{array}{c}0.106 \\
(2.59)^{* *}\end{array}$ & $\begin{array}{l}0.058 \\
(1.48)\end{array}$ \\
\hline IC risk is high & $\begin{array}{l}0.012 \\
(0.34)\end{array}$ & $\begin{array}{l}0.039 \\
(0.95)\end{array}$ & $\begin{array}{l}-0.009 \\
(-0.22)\end{array}$ \\
\hline Missing values & Yes & Yes & Yes \\
\hline Observations & 990 & 981 & 986 \\
\hline
\end{tabular}

Probit Model Specification

Source: Russia LME Survey, 2005

The regression results, reported in Table 13, confirm the importance of several factors that shape the demand for in-service training provision. First, bearing out the correlations reported in earlier tables, the likelihood of in-service training is higher in larger firms (those with over 250 employees), and in localities that are rated as being "moderate" investment risk regions rather than either "low" or "high" risk regions. Second, firms that employ a larger proportion of workers with higher education are also more likely to train. The empirical evidence internationally is that both forms of skills - education attainment of the workforce and post-school training - are highly correlated. ${ }^{22}$ Educated workers are not only more productive in performing given tasks, but are thought to be more adept at critically evaluating new information and learning from it.

\footnotetext{
${ }^{22}$ See Tan and Batra 1995 for estimates on the education-training relationship from five developing countries in East Asia and Latin America; Tan 2000 and World Bank (1997, 2005) for related training analyses for Malaysia.
} 
Firms that engage in $\mathrm{R} \& \mathrm{D}$, and to a lesser extent, export-oriented firms are also more likely to train. The technology literature suggests that much of the productivity gains from introducing a new innovation are realized through an intensive learning-by-doing process (Enos 1962; Bell and Pavitt, 1992) and firms, to effectively use the new technology, have to adjust management, reorganize production lines, and upgrade worker skills. Export orientation can also have a salutary effect on training provision. Employers that export have greater incentives to train their workers to produce high quality products meeting the exacting standards of foreign buyers, and to increase labor productivity to meet competitive pressures (Tan and Batra 1995; Batra and Stone 2004).

The second and third columns of Table 13 highlight differences in the determinants of external and in-house training. Training from external sources tend to be more common among long-established firms where the government has controlling interests, and in export oriented firms with a high share of highly educated workers. This reliance on external training appears to be a carry-over from the pre-transition period where many state-owned enterprises (SOE) had arrangements to hire specifically-trained graduates from related vocational and technical training institutions. By contrast, in-house training is shaped less by the share of highly educated workers, and more by the firm's exportorientation, location in moderate investment risk regions, and R\&D spending. Employers appear to rely more on in-house training when industry or work-relevant skills are not available locally or when innovative activities require intensive on-the-job learning and training specific to the new technologies being developed or used.

\section{Box 4. Public and Private Sector Training Sources}

The Russia ICS did not distinguish between public and private sector sources of in-service training. However, the ICS of many other developing countries elicited information on which external training providers firms used, including public VET institutions, private training companies, buyers, other firms to which enterprises were linked, and companies selling equipment and machinery. The detailed data indicated that enterprises in many developing countries preferred private sector providers over public ones, even when private training cost more than often-free training services from public VET institutions, in large part because private training was tailored to their specific needs and delivered at times and in places that met their requirements. The data also revealed that buyers, partner firms and equipment suppliers are important sources of training and know-how transfer. That firms prefer public over private training sources is supported by analyses that suggest that for some countries, the productivity impacts of private external training exceeds those from public external training, which are often statistically insignificant.

Source: Tan, Pei and Savchenko (2003), "Enterprise Training in Developing Countries: Evidence from Investment Climate Surveys", unpublished World Bank Institute working paper. 


\section{Productivity and Wage Outcomes of Training}

Provision of in-service training only makes sense if employers' investments in the training and skills-upgrading of employees yield positive returns in the form of higher productivity and profits. If formal training is found to be associated with higher firmlevel productivity, as suggested by the preponderance of evidence from both industrialized and developing countries ${ }^{23}$, the question is which source of training (inhouse company programs or training from external training providers) has the largest impact on productivity? See Box 4. If training yields positive impacts on productivity, employers also need to determine whether, or how much, to share productivity gains from training with workers in the form of higher wages. This calculus will depend on how transferable skills gained from training are to other potential employers (see Becker 1976; Tan 1980; Acemoglu and Pischke 1998).

A production function approach is used to estimate the productivity impact of training. The dependent variable - the logarithm of value added - is regressed on the logarithms of capital (book value of physical plant and equipment assets), alternative measure of training (any formal training, in-house or external training, and combinations of training sources), and a vector of control variables for worker attributes (mean years of education) and for location in moderate or high investment risk regions. The production functions, estimated by ordinary least squares, implicitly treat the different training variables as being exogenously determined. This assumption may be suspect if the firms that train are also more productive, and systematically self-select themselves into the training group on the basis of unobserved productivity traits so that production function estimates of training are potentially biased. Qualitatively similar productivity (and wage) results obtain when account is taken of self-selection into training. See Annex 1.

Table 14 reports the production function results and estimates of the productivity effects of training. Before turning to the training results, some parameters estimated by these models are noteworthy. First, the estimated production function parameters of capital and labor coefficient are positive and statistically significant, and consistent with those reported by other studies of the Russian economy. Second, consistent with the belief that education raises productivity, the production function results indicate that increased educational attainment of the firm's workforce of one year is associated with higher levels of firm-level productivity of about 4-5 percent. Third, regions with moderate or high investment risk have productivity levels 27 to 33 percent lower, respectively, than regions with low investment risk. It appears that firms in "moderate" to "high" investment risk regions have greater incentives to train in-house to compensate for skills shortfalls in the local markets and for their lower overall productivity levels.

\footnotetext{
${ }^{23}$ Cross-sectional studies have found a strong positive association between in-service training and productivity and wage levels of firms (Tan and Batra 1995; Batra and Stone 2004).
} 
Table 14. In-Service Training and Productivity

Dependent variable: $\log (\mathrm{VA})$

Model specifications

\begin{tabular}{|c|c|c|c|}
\hline $\log ($ Capital $)$ & $\begin{array}{c}0.197 \\
(6.77)^{* * *}\end{array}$ & $\begin{array}{c}0.196 \\
(6.68)^{* * *}\end{array}$ & $\begin{array}{c}0.196 \\
(6.58)^{* * *}\end{array}$ \\
\hline $\log ($ Labor $)$ & $\begin{array}{c}0.889 \\
(15.57)^{* * *}\end{array}$ & $\begin{array}{c}0.876 \\
(15.45)^{* * *}\end{array}$ & $\begin{array}{c}0.877 \\
(15.28) * * *\end{array}$ \\
\hline Mean years of education & $\begin{array}{c}0.055 \\
(2.69)^{* *}\end{array}$ & $\begin{array}{c}0.056 \\
(2.74)^{* *}\end{array}$ & $\begin{array}{c}0.057 \\
(2.72)^{* *}\end{array}$ \\
\hline Regional IC risk is moderate & $\begin{array}{c}-0.277 \\
(-3.08)^{* * *}\end{array}$ & $\begin{array}{c}-0.277 \\
(-3.01)^{* * *}\end{array}$ & $\begin{array}{c}-0.272 \\
(-3.00)^{* * *}\end{array}$ \\
\hline Regional IC risk is high & $\begin{array}{c}-0.332 \\
(-4.41)^{* * *}\end{array}$ & $\begin{array}{c}-0.330 \\
(-4.39)^{* * *}\end{array}$ & $\begin{array}{c}-0.333 \\
(-4.42)^{* * *}\end{array}$ \\
\hline Any formal training & $\begin{array}{c}0.225 \\
(3.48)^{* * *}\end{array}$ & & \\
\hline In-house training & & $\begin{array}{l}0.092 \\
(1.19)\end{array}$ & \\
\hline External training & & $\begin{array}{c}0.22 \\
(3.27)^{* * *}\end{array}$ & \\
\hline Only in-house training & & & $\begin{array}{l}-0.003 \\
(-0.03)\end{array}$ \\
\hline Only external training & & & $\begin{array}{c}0.168 \\
(1.99)^{*}\end{array}$ \\
\hline Both in-house \& external training & & & $\begin{array}{c}0.281 \\
(4.06)^{* * *}\end{array}$ \\
\hline Constant & $\begin{array}{c}8.64 \\
(30.41)^{* * *}\end{array}$ & $\begin{array}{c}8.695 \\
(30.27)^{* * *}\end{array}$ & $\begin{array}{c}8.708 \\
(30.21)^{* * * *}\end{array}$ \\
\hline Missing values & Yes & Yes & Yes \\
\hline Regional cluster & Yes & Yes & Yes \\
\hline Observations & 784 & 784 & 784 \\
\hline R-squared & 0.64 & 0.64 & 0.64 \\
\hline
\end{tabular}

The production function results provide support for the hypothesis that training improves productivity. The measure for any formal in-service training is positive and statistically significant at the 1 percent level, and suggests that training is associated with a 22 percent increase in firm-level productivity. When training is disaggregated by source, only external training is significant. However, when firms are distinguished by whether they rely only on in-house, only on external training, or use both in-house and external training, the results suggest that using both sources of training is most productive (28 percent), while using only external training sources is associated with a 17 percent increase in productivity. 
For the wage analysis, a wage model is estimated both at the level of the firm, using the logarithm of mean monthly wage and training of the firm, and for the pooled sample of occupations within each firm to exploit the availability of occupation-specific information on wages. The logarithm of monthly per-worker firm-level or occupationspecific wages is regressed on the training variables, a vector of firm attributes, and average years of education of the workforce. For the occupational wage model, data on up to five occupational groups per firm are pooled and indicator variables included for managers, professionals, skilled workers and unskilled workers (the omitted category being "other white-collar employees") in place of mean years of education with which occupations are closely correlated. The pooled sample consists of 3,026 occupations from the 923 firms, and the regression model accounts for the common error structure for all occupations in the same firm.

Table 15. Cross-Sectional Wage Models with Training

\begin{tabular}{|c|c|c|c|c|}
\hline $\begin{array}{l}\text { Dependent variable: } \\
\text { log(monthly wage })\end{array}$ & $\underline{\text { Firm-level }}$ & age Model & Occupatior & age Model \\
\hline Constant & $\begin{array}{c}10.224 \\
(46.85)^{* * *}\end{array}$ & $\begin{array}{c}10.205 \\
(47.58)^{* * *}\end{array}$ & $\begin{array}{c}7.993 \\
(48.34)^{* * *}\end{array}$ & $\begin{array}{c}7.903 \\
(49.81)^{* * *}\end{array}$ \\
\hline Any formal training & $\begin{array}{c}0.16 \\
(3.29)^{* * *}\end{array}$ & & $\begin{array}{l}0.091 \\
(1.58)\end{array}$ & \\
\hline In-house training & & $\begin{array}{l}0.044 \\
(0.75)\end{array}$ & & $\begin{array}{c}0.160 \\
(3.02)^{* * *}\end{array}$ \\
\hline External training & & $\begin{array}{c}0.178 \\
(4.21)^{* * *}\end{array}$ & & $\begin{array}{l}0.096 \\
(1.48)\end{array}$ \\
\hline Small enterprise $(<250)$ & $\begin{array}{c}-0.162 \\
(-3.18)^{* * *}\end{array}$ & $\begin{array}{c}-0.147 \\
(-2.90)^{* * *}\end{array}$ & $\begin{array}{c}-0.199 \\
(-3.60)^{* * *}\end{array}$ & $\begin{array}{c}-0.177 \\
(-3.20)^{* * *}\end{array}$ \\
\hline Some foreign ownership & $\begin{array}{l}-0.109 \\
-(1.29)\end{array}$ & $\begin{array}{l}-0.101 \\
-(1.21)\end{array}$ & $\begin{array}{l}0.084 \\
(1.17)\end{array}$ & $\begin{array}{l}0.087 \\
(1.23)\end{array}$ \\
\hline Government controlled & $\begin{array}{l}0.059 \\
(0.72)\end{array}$ & $\begin{array}{l}0.047 \\
(0.58)\end{array}$ & $\begin{array}{l}-0.06 \\
(-0.84)\end{array}$ & $\begin{array}{l}-0.059 \\
(-0.81)\end{array}$ \\
\hline Exporter & $\begin{array}{c}0.102 \\
(2.08)^{* *}\end{array}$ & $\begin{array}{c}0.095 \\
(1.84)^{*}\end{array}$ & $\begin{array}{c}0.06 \\
(1.27)\end{array}$ & $\begin{array}{l}0.044 \\
(0.94)\end{array}$ \\
\hline Positive R\&D spending & $\begin{array}{l}0.054 \\
(0.94)\end{array}$ & $\begin{array}{l}0.052 \\
(0.91)\end{array}$ & $\begin{array}{c}0.178 \\
(3.07)^{* * *}\end{array}$ & $\begin{array}{c}0.168 \\
(2.93)^{* * *}\end{array}$ \\
\hline $\mathrm{R} \& \mathrm{D}$ sales ratio & $\begin{array}{c}1.728 \\
(3.10)^{* * *}\end{array}$ & $\begin{array}{c}1.765 \\
(3.37)^{* * *}\end{array}$ & $\begin{array}{l}0.069 \\
(1.03)\end{array}$ & $\begin{array}{l}0.074 \\
(1.09)\end{array}$ \\
\hline New Firm (after 1992) & $\begin{array}{l}0.018 \\
(0.28)\end{array}$ & $\begin{array}{l}0.021 \\
(0.33)\end{array}$ & $\begin{array}{c}-0.199 \\
(-3.60)^{* * *}\end{array}$ & $\begin{array}{c}-0.177 \\
(-3.20)^{* * *}\end{array}$ \\
\hline Mean years of education & $\begin{array}{c}0.061 \\
(3.82)^{* * *}\end{array}$ & $\begin{array}{c}0.061 \\
(3.87)^{* * *}\end{array}$ & n.a. & n.a. \\
\hline Occupation dummies & No & No & Yes & Yes \\
\hline Observations & 923 & 923 & 3,026 & 3,026 \\
\hline R-squared & 0.08 & 0.09 & 0.241 & 0.253 \\
\hline
\end{tabular}

Absolute value of $t$ statistics in parentheses. All regressions include control variables for missing values and for regions.

* significant at $1 \%, * *$ significant at $5 \% ; * * *$ significant at $1 \%$ levels.

Source: Russia LME Survey, 2005. 
Similar positive impacts of training are found on average monthly wages in firms. Table 15 reports the results for firm-level wages in the first two columns, and the results for the occupation-level wages in the next two columns. In general, Russian employers pay higher wages when enterprises are large (with over 250 employees) and export-oriented, engage in R\&D activities, and employ a more highly educated workforce. Consistent with the earlier training-productivity finding, enterprises that train also pay monthly wages that are 16 percent higher than non-training firms, a difference that is statistically significant at the 1 percent level.

The wage impacts of training differ by training source depending on whether firm-level or occupation-level wages are being studied. The firm-level results suggest that external training is associated with the largest wage gains (18 percent) while the wage effects of in-house training programs are not statistically significant. On the other hand, occupational wages are most strongly affected by in-house training (16 percent), a result that is statistically significant, but they are not affected by training from external sources. By averaging across occupations, firm-level mean wages may conceal considerable within-firm variation in wages by skills or occupational levels. Plausibly, this dispersion of skills-wage differentials both within and across firms is better explained by in-house training than by external training, and may reflect skills-wage premiums associated with innovating firms that rely on in-house training (see Table 15).

\section{Box 5. Panel Estimates of the Productivity and Wage Effects of Training}

Several panel studies, based on longitudinal firm surveys in Britain, Mexico and Malaysia that elicited repeated information on the training practices of the same firms over time, have investigated and found evidence that training leads causally to higher firm-level growth in productivity and wages. In Malaysia and Mexico, training histories of firms over a 10 year period were used to construct training indicators for use in panel production function and wage models. Firms that trained repeatedly experienced higher rates of productivity growth than those that did not train or that had one-off training; productivity growth was especially high when training firms also invested in new technology. Firms that trained continuously were also more likely to move up into higher deciles of the wage distribution or, alternatively, less likely to slip into lower wage deciles over time.

Sources: Dearden, Reed and Van Reenen (2000) for Britain; Tan (2000) for Malaysia; and Tan and Lopez-Acevedo (2003) for Mexico.

\section{Skills Development and Firm Performance over Time}

Do the cross-sectional productivity and wage effects of skills training persist in the timeseries? To investigate this question, a sub-sample of the Russia ICS survey is linked to 
financial data on the same enterprises for earlier years using the SPARK database. ${ }^{24}$ The panel analysis focuses on combined data for the same enterprises in two years, 2000 and $2004^{25}$, and it relies on the strong assumption that the training information (and that for other control variables) elicited in the 2005 Russia ICS is pertinent to the entire 4 year period under consideration. This assumption may be relaxed when the Russia ICS sample is tracked over time and repeated measures of training become available, allowing true panel estimates of the productivity and wage effects of training (see Box 5).

Three measures of firm performance over time - growth in sales, growth in value-added ${ }^{26}$ and growth in employment - are investigated. Underlying the first two measures is a production function model, and as such the growth equations include as explanatory variables growth in the logarithms of capital and labor, training, and other variables reported in the earlier cross-section regressions. The third measure is growth in the logarithm of employment (a measure of job creation), and this regression includes growth in the logarithm of capital, training and the other control variables. The results are reported in Table 16.

Formal in-service training has a positive and statistically significant impact on all three measures of firm performance over time. The presence of in-service training increases output growth, measured either by sales or by value added, by an average of between 17 and 21 percent over the 2000 to 2004 period. Training raises employment growth by 15 percent over the same period. When training source is distinguished, only training from external sources has an effect on output growth, and it is only statistically significant at the 10 percent level in the value-added output specification. By contrast, both in-house and external training have a positive and significant impact on employment growth, with in-house training having the larger impact (14 percent) on job creation as compared to external training ( 9 percent).

The other correlates of firm performance are not without interest. Research and development (R\&D) and export-orientation have a marginally significant positive impact on output growth over time, varying by output measure. Exporting is associated with sales growth (13 percent), and R\&D spending with higher value-added growth. Consistent with the results in the productivity chapter, firms doing R\&D have lower initial levels of productivity (16-18 percent), though productivity growth is raised (6 percent) by a 1 percent increase in R\&D spending as a proportion of sales. Finally, employment growth over time is higher in firms that were small (less than 250 employees) in 1999.

\footnotetext{
${ }^{24}$ SPARK is the largest database on enterprises containing uniform information on a set of key financial data drawn from more than 10 official sources, including the Federal Statistics Service, the Federal Tax Service, the Federal Financial Markets Service and other government agencies.

${ }^{25}$ The year 2000 was selected because it is the last year that information on total employment is available in the SPARK database.

${ }^{26}$ Value added in this panel analysis is approximated by the sum of gross profits and wage bill, since information on the value of intermediate inputs needed to calculate value added are not reported in SPARK.
} 
Table 16. Training and Firm Performance from 2000 to 2004

\begin{tabular}{|c|c|c|c|c|c|c|}
\hline \multirow{2}{*}{$\begin{array}{l}\text { Dependent variable: } \\
\log (\Delta \text { Labor })\end{array}$} & \multicolumn{4}{|c|}{$\frac{\text { Model specification }}{\log (\Delta V A)}$} & \multicolumn{2}{|c|}{$\underline{\log (\Delta \text { Labor })}$} \\
\hline & $\begin{array}{c}0.68 \\
(11.05)^{* * *}\end{array}$ & $\begin{array}{c}0.681 \\
(10.98)^{* * *}\end{array}$ & $\begin{array}{c}0.662 \\
(8.96)^{* * *}\end{array}$ & $\begin{array}{c}0.67 \\
(9.04)^{* * *}\end{array}$ & & \\
\hline $\log (\Delta$ Capital $)$ & $\begin{array}{c}0.221 \\
(6.86)^{* * *}\end{array}$ & $\begin{array}{c}0.222 \\
(6.87)^{* * *}\end{array}$ & $\begin{array}{c}0.136 \\
(3.63)^{* * *}\end{array}$ & $\begin{array}{c}0.14 \\
(3.74)^{* * *}\end{array}$ & $\begin{array}{c}0.161 \\
(9.22)^{* * *}\end{array}$ & $\begin{array}{c}0.16 \\
(9.16)^{* *}\end{array}$ \\
\hline Any formal training & $\begin{array}{l}0.165 \\
(2.10)^{*}\end{array}$ & & $\begin{array}{c}0.217 \\
(2.45)^{* *}\end{array}$ & & $\begin{array}{c}0.147 \\
(3.27)^{* * *}\end{array}$ & \\
\hline In-house training & & $\begin{array}{l}0.044 \\
(0.56)\end{array}$ & & $\begin{array}{l}-0.032 \\
(-0.35)\end{array}$ & & $\begin{array}{c}0.145 \\
(3.26)^{* *}\end{array}$ \\
\hline External training & & $\begin{array}{c}0.09 \\
(1.13)\end{array}$ & & $\begin{array}{c}0.181 \\
(1.99)^{*}\end{array}$ & & $\begin{array}{c}0.094 \\
(2.07)^{*}\end{array}$ \\
\hline SME in 1999 & $\begin{array}{l}0.062 \\
(0.80)\end{array}$ & $\begin{array}{l}0.057 \\
(0.73)\end{array}$ & $\begin{array}{l}-0.018 \\
(-0.20)\end{array}$ & $\begin{array}{l}-0.039 \\
(-0.44)\end{array}$ & $\begin{array}{c}0.247 \\
(5.70)^{* * *}\end{array}$ & $\begin{array}{c}0.264 \\
(6.09)^{* *}\end{array}$ \\
\hline New Firm & $\begin{array}{l}0.086 \\
(0.91)\end{array}$ & $\begin{array}{l}0.084 \\
(0.88)\end{array}$ & $\begin{array}{l}-0.122 \\
(-1.01)\end{array}$ & $\begin{array}{l}-0.157 \\
(-1.29)\end{array}$ & $\begin{array}{l}0.048 \\
(0.85)\end{array}$ & $\begin{array}{l}0.053 \\
(0.95)\end{array}$ \\
\hline Positive R\&D spending & $\begin{array}{l}-0.102 \\
(-1.21)\end{array}$ & $\begin{array}{l}-0.098 \\
(-1.16)\end{array}$ & $\begin{array}{c}-0.179 \\
(-1.89)^{*}\end{array}$ & $\begin{array}{l}-0.161 \\
(-1.70)\end{array}$ & $\begin{array}{l}0.024 \\
(0.50)\end{array}$ & $\begin{array}{l}0.014 \\
(0.28)\end{array}$ \\
\hline R\&D / Sales ratio (x100) & $\begin{array}{l}-0.524 \\
(-0.25)\end{array}$ & $\begin{array}{l}-0.446 \\
(-0.22)\end{array}$ & $\begin{array}{l}0.057 \\
(1.89)^{*}\end{array}$ & $\begin{array}{l}0.057 \\
(1.88)^{*}\end{array}$ & $\begin{array}{l}-0.010 \\
(-0.84)\end{array}$ & $\begin{array}{l}-0.010 \\
(-0.88)\end{array}$ \\
\hline Exporter & $\begin{array}{c}0.132 \\
(1.81)^{*}\end{array}$ & $\begin{array}{c}0.13 \\
(1.76)^{*}\end{array}$ & $\begin{array}{l}0.053 \\
(0.63)\end{array}$ & $\begin{array}{l}0.054 \\
(0.64)\end{array}$ & $\begin{array}{l}0.072 \\
(1.69)\end{array}$ & $\begin{array}{l}0.063 \\
(1.47)\end{array}$ \\
\hline Constant & $\begin{array}{c}0.186 \\
(2.42)^{* *}\end{array}$ & $\begin{array}{c}0.22 \\
(2.97)^{* * *}\end{array}$ & $\begin{array}{l}0.123 \\
(1.38)\end{array}$ & $\begin{array}{c}0.164 \\
(1.92)^{*}\end{array}$ & $\begin{array}{c}-0.28 \\
(-5.38)^{* *}\end{array}$ & $\begin{array}{c}-0.294 \\
(-5.88)^{* *}\end{array}$ \\
\hline Missing values & Yes & Yes & yes & yes & yes & yes \\
\hline Observations & 774 & 774 & 544 & 544 & 777 & 777 \\
\hline R-squared & 0.28 & 0.28 & 0.22 & 0.23 & 0.22 & 0.23 \\
\hline
\end{tabular}

\section{Training and Innovative Capacity}

Training and innovation are complementary activities, in the sense that the firm's capacity to innovate or absorb new technology, and to benefit from innovation and adoption, depends critically on the skills and training of the workforce. The previous analyses have already shown in-service training and R\&D spending (a crude measure of innovation) to be highly correlated. Training is also highly correlated with other indicators of innovativeness - such as third party R\&D or licensing of patents and knowhow, introduction of new production technologies or high-technology exports. The more pertinent issue is not just whether training and innovation are correlated, but whether innovation is possible without a highly skilled and trained workforce?

One approach to addressing this issue is to ask how firms decide to innovate or to train their workers, and whether these two investment decisions co-vary in systematic ways. Are they made independently, or jointly? If the two decisions are independent, then 
separate models can be estimated for each decision with the other decision variable included as an exogenous explanatory variable. If they are not independent, then both decisions to train and to innovate must be modeled jointly. Furthermore, their impacts on outcomes such as improved productivity or wage gains must be estimated accounting not only for selection bias (see Annex 1 on using a "treatment effects" model) but also for the joint nature in which both decisions are made.

Table 17. Innovation and Training Variables

\begin{tabular}{|c|c|c|c|c|}
\hline \multirow[t]{2}{*}{ Innovation measures } & \multicolumn{2}{|c|}{$\begin{array}{l}\text { Sample size if meet } \\
\text { innovation criterion }\end{array}$} & \multicolumn{2}{|c|}{$\begin{array}{l}\% \text { training if meet } \\
\text { innovation criterion }\end{array}$} \\
\hline & Yes & No & Yes & No \\
\hline R\&D spending over 1 million rubles & 211 & 779 & 0.79 & 0.67 \\
\hline Introduced new process technology & 293 & 697 & 0.80 & 0.65 \\
\hline Purchased patents, licenses or know-how & 161 & 829 & 0.74 & 0.69 \\
\hline Composite innovation indicator & 463 & 527 & 0.77 & 0.63 \\
\hline
\end{tabular}

Source: Russia LME Survey, 2005, figures calculated by the authors.

In this section, we test the maintained hypothesis that innovation and training are complementary activities. As the measure of innovation, a composite indicator variable is used, with a value of 1 if the firm has substantial R\&D spending (over a million rubles), OR has purchased technology licenses, patents and know-how, OR has introduced new production processes, and 0 otherwise. Table 17 shows the distribution of firms for each of the variables that make up this composite innovation indicator. 463 firms are defined as being "innovative", and those so defined are more likely to train (77 percent) as compared to those that are not (63 percent). Each of the innovation variables that go into the composite indicator are similarly correlated with training.

A bivariate probit model is jointly estimated for the two decision variables - whether or not to innovate, and to train - each equation having some explanatory variables in common, but also others that are assumed to affect one decision but not the other. ${ }^{27}$ The bivariate regression results for the innovation and training equations are reported in Table 18. Many of the training results have been reported previously and will not be elaborated on further. The innovation equation, however, is new. The results suggest that innovating firms tend to be larger, use relatively new machinery and equipment, export and employ a more educated workforce. More pertinent is the estimate of rho, which measures the covariance in the errors of the innovation and training equations. Both Wald and likelihood ratio tests reject the null hypothesis that rho is equal 0 , that is, they confirm that the innovation and training decisions are made jointly.

\footnotetext{
${ }^{27}$ Each equation must be identified by having one or more instruments that affect (or are highly correlated with) that choice variable but not the other. For the innovation equation, the instruments are indicators for having newer equipment and having received government support for R\&D. For the training equation, the corresponding instruments are an index of difficulty searching for and hiring professionals and skilled workers, and whether the enterprise is under-staffed or over-staffed.
} 
Table 18. Bivariate Probit Regressions of Innovation and Training

\begin{tabular}{|c|c|c|}
\hline Dependent variables: Innovation and Training & Coefficient & z-score \\
\hline \multicolumn{3}{|l|}{ Innovation Equation } \\
\hline Firm size $(101-250)$ & 0.184 & 0.97 \\
\hline Firm size (251-1000) & 0.492 & 2.56 \\
\hline Firm size $(>1000)$ & 1.031 & 4.65 \\
\hline New equipment dummy* & 0.264 & 3.04 \\
\hline Percent workforce with higher education & 0.008 & 2.39 \\
\hline New firm dummy (established after 1992) & -0.019 & -0.18 \\
\hline Exporter & 0.361 & 4.05 \\
\hline Foreign owned (foreign ownership $>=10 \%$ ) & 0.111 & 0.88 \\
\hline Government control dummy (government $>=25 \%$ ) & -0.009 & -0.08 \\
\hline Received any government support for R\&D & 0.047 & 0.37 \\
\hline Constant & -0.939 & -4.82 \\
\hline \multicolumn{3}{|l|}{ Training Equation } \\
\hline SME indicator $(<250$ workers $)$ & -0.521 & -5.73 \\
\hline Percent workforce with higher education & 0.010 & 2.84 \\
\hline New firm (established after 1992) & -0.115 & -1.09 \\
\hline Exporter & 0.202 & 2.17 \\
\hline Foreign owned (foreign ownership $>=10 \%$ ) & -0.194 & -1.45 \\
\hline Government control (government $>=25 \%$ ) & 0.187 & 1.48 \\
\hline Difficulty hiring skilled and professional workers** & 0.108 & 1.16 \\
\hline Firm overstaffed indicator & 0.015 & 0.15 \\
\hline Firm understaffed indicator & 0.460 & 3.05 \\
\hline Constant & 0.403 & 3.49 \\
\hline Number of observations & \multicolumn{2}{|c|}{979} \\
\hline Rho & \multicolumn{2}{|c|}{0.1125} \\
\hline Wald test - chi2(24) & \multicolumn{2}{|c|}{170.2} \\
\hline $\begin{array}{l}\text { Log pseudo-likelihood }=-1174.4488 \text { Prob }>\text { chi2 } \\
\text { Source: Russia LME Survey, } 2005\end{array}$ & \multicolumn{2}{|c|}{0} \\
\hline \multicolumn{3}{|c|}{$\begin{array}{l}\text { Notes: * new equipment }=1 \text { if less than } 50 \% \text { of equipment is fully depreciated } \\
* * \text { difficulty of hiring skilled and professional workers }=1 \text { if firm ranked difficulty of either } \\
\text { skills group a } 4 \text { or } 5 \text { on } 1-5 \text { scale ( } 5 \text { being the most difficult) }\end{array}$} \\
\hline
\end{tabular}

The bivariate probit model also yields estimates of the probabilities that firms choose one investment activity but not the other, choose both activities, or choose neither one. To simplify description, let $\operatorname{Pr}(\mathrm{ij})$ be the joint probability of innovation $\mathrm{i}$ and training $\mathrm{j}$. For the ICS sample as a whole, the least likely probabilities are $\operatorname{Pr}(10)$ - firms innovate but do not train (10 percent) - and $\operatorname{Pr}(00)$, firms engage in neither activity (11 percent). It is much more common for firms to train but not innovate, $\operatorname{Pr}(01)$ of 36 percent, or invest in both innovation and training at the same time, $\operatorname{Pr}(11)$ of 22 percent. The model also yields estimates of the probability of one investment activity conditional on the other taking place. Denote these as $\operatorname{Pr}(\mathrm{i} \mid \mathrm{j})$ and $\operatorname{Pr}(\mathrm{j} \mid \mathrm{i})$. The conditional probability of innovating given training is not high, $\operatorname{Pr}(\mathrm{i} \mid \mathrm{j})$ is 43 percent, suggesting that firms have many other reasons for training, not just to support innovation. In contrast, the conditional probability of training given innovation is much higher, $\operatorname{Pr}(\mathrm{j} \mid \mathrm{i})$ of 73 percent, supporting the maintained hypothesis that skills and training are needed to complement investments in innovative activities of the firm. 
Table 19 reports the predicted joint probabilities of innovation and training disaggregated by several firm attributes. The tabulations are restricted to those firm characteristics that allow us to discriminate among the different predicted joint probabilities. First, they suggest that larger firms are more likely to invest in both innovation and training (46 percent) or just training alone (33 percent), as compared to small firms which are more likely to just train (36 percent) than invest in both innovation and training ( 22 percent). Similarly, exporting firms are more likely to both innovate and to train (47 percent) than just invest in training (30 percent), while non-exporters are more likely to just train (38 percent). Finally, over-staffed firms are more likely to invest in both innovation and training (47 percent) or in just training (37 percent), as compared to optimally-staffed or under-staffed firms who are equally likely to do both or to just invest in training (about 33-35 percent).

Table 19. Predicted Joint Probabilities of Innovation and Training

\begin{tabular}{|c|c|c|c|c|}
\hline & Innovate $=0$ & Innovate $=0$ & Innovate $=1$ & Innovate $=1$ \\
\hline Firm characteristics & Train $=0$ & Train $=1$ & Train $=0$ & Train $=1$ \\
\hline Total sample & 0.19 & 0.34 & 0.11 & 0.36 \\
\hline \multicolumn{5}{|l|}{ Small enterprise $(<250)$} \\
\hline No & 0.11 & 0.33 & 0.10 & 0.46 \\
\hline Yes & 0.30 & 0.36 & 0.13 & 0.22 \\
\hline \multicolumn{5}{|l|}{ Exporter } \\
\hline No & 0.25 & 0.38 & 0.11 & 0.26 \\
\hline Yes & 0.11 & 0.30 & 0.11 & 0.47 \\
\hline \multicolumn{5}{|l|}{ Staffing in the firm } \\
\hline Optimal & 0.20 & 0.33 & 0.12 & 0.34 \\
\hline Understaffed & 0.20 & 0.35 & 0.11 & 0.34 \\
\hline Overstaffed & 0.09 & 0.37 & 0.06 & 0.47 \\
\hline
\end{tabular}

Table 20 reports estimates of production functions and wage equations which include predicted joint probabilities of innovation and training, with the omitted category being the prediction of investing in neither innovation or training. By construction, these predicted joint probabilities are uncorrelated with the error terms of the model, yielding unbiased (but inefficient) estimates of the innovation and training variables. For comparison, the same models are estimated using indicator variables of innovation and training, both treated as being exogenously determined outside the model, to characterize firms as just innovating, just training, or doing both. The production function results indicate that only joint investments in innovation and training improve firm-level productivity. This may be contrasted with the alternative "exogenous" model, where "just training" or "both training and innovating" is associated with productivity increases, but not "just innovating". The wage regression using predicted values suggest that all three states - just training, just innovating, and investing in both activities - are associated with positive wage gains. Curiously, just innovating but not training has the largest coefficient. The alternative "exogenous" wage model also yields different results, 
namely that "just training" or "investing in both" show wage gains, but "just innovating" does not.

Table 20. Production Functions and Wage Models

Estimated with Exogenous or Predicted Innovation and Training

\begin{tabular}{|c|c|c|c|c|}
\hline $\begin{array}{l}\text { Dependent variables: } \\
\text { Predicted joint probabilities }\end{array}$ & \multicolumn{2}{|c|}{ Log(value-added) } & \multicolumn{2}{|c|}{ Log(wages) } \\
\hline (innovate $=0$, train $=1$ ) & -0.186 & & 1.437 & \\
\hline & $(-0.23)$ & & $(2.31)^{*}$ & \\
\hline (innovate $=1$, train $=0$ ) & 0.712 & & 2.490 & \\
\hline & $(0.50)$ & & $(2.66) * *$ & \\
\hline (innovate $=1$, train $=1$ ) & 1.199 & & 1.889 & \\
\hline & $(2.66)^{* *}$ & & $(4.32)^{* *}$ & \\
\hline Exogenous Innovation and Training & & & & \\
\hline (innovate $=0$, train $=1$ ) & & $\begin{array}{c}0.242 \\
(2.60)^{* *}\end{array}$ & & $\begin{array}{c}0.153 \\
(2.63)^{* *}\end{array}$ \\
\hline (innovate $=1$, train $=0$ ) & & $\begin{array}{l}0.139 \\
(1.13)\end{array}$ & & $\begin{array}{l}0.100 \\
(1.50)\end{array}$ \\
\hline (innovate $=1$, train $=1$ ) & & $\begin{array}{c}0.303 \\
(3.12)^{* * *}\end{array}$ & & $\begin{array}{c}0.165 \\
(2.66)^{* *}\end{array}$ \\
\hline Mean years of workforce education & $\begin{array}{c}0.036 \\
(1.82)^{*}\end{array}$ & $\begin{array}{c}0.05 \\
(2.55)^{* *}\end{array}$ & $\begin{array}{c}0.038 \\
(2.79)^{* * *}\end{array}$ & $\begin{array}{c}0.054 \\
(3.39)^{* * *}\end{array}$ \\
\hline Observations & 775 & 784 & 911 & 923 \\
\hline R-squared & 0.64 & 0.63 & 0.13 & 0.12 \\
\hline Source: Russia LI & & & & \\
\hline $\begin{array}{ll}\text { Notes: } & \text { Production functions include logar } \\
\text { region. Wage equations include fir } \\
\text { region, and industry. * significant }\end{array}$ & capital & $\begin{array}{l}\text { and contrc } \\
\text { firm, and }\end{array}$ & $\begin{array}{l}\text { missing } \\
\text { bls for mi }\end{array}$ & $\begin{array}{l}\text { and } \\
\text { alues, }\end{array}$ \\
\hline
\end{tabular}

\section{Summary and Policy Implications}

Together, the analyses of the Russia ICS data and comparisons of findings with those from other developed and developing countries, suggest that employer perceptions about a shortage of skilled and qualified workers are real. They tell a broadly consistent story about the nature of skills shortages: a high and rising demand for educated and skilled workers; an educational and training system that is under-funded below the tertiary level and faced with numerous challenges including deteriorating quality and becoming more responsive to industry's skills needs; an industrial sector experiencing high labor turnover (which inhibits training), constraints on its ability to flexibly adjust its workforce and skills mix, and for some non-competitive enterprises the inability to pay competitive wages to attract and retain needed skills. They suggest that most enterprises have not responded to these skills shortages by taking responsibility for training their employees in-house, and training more of them, despite the productivity and wage gains that might come from such investments. 
These results have implications for training policy in Russia. To begin, it is clear that Russian industrial enterprises under-invest in the training of their employees. While the incidence is high, the proportion of employees provided in-house trained in different skills categories is one of the lowest among the countries for which data are available, both high-income and developing countries. If in-service training is critical to the effective use of new technologies and to productivity growth, as the literature and the estimates reported in this paper suggests, than Russia's under-investment in workforce skills places it at a relative disadvantage compared to its OECD, BRIC and East Asian competitors. Improving the investment climate in Russia should have a salutary effect on business operations and growth, and create incentives for the private sector to invest in both physical and human capital. Policies to foster greater technological change should also induce more in-service training, given the evidence of a strong training-innovation nexus.

Box 6. Malaysia's Human Resource Development Fund

The Human Resource Development Fund (HRDF) was established in 1993 to promote increased enterprise-based training among firms, first in manufacturing and then more recently in service sectors as well. The Act created a council (HRDC), with representatives from the private sector and from responsible government agencies, and a Secretariat to administer the different HRDF schemes. Eligible employers with 50 or more employees are required to contribute 1 percent of payroll to the HRDF from which they are then eligible to claim a portion of allowable training expenditures up to the limit of their total levy payments for any given year. The HRDC set rates of reimbursement, varying by type of training and higher for smaller firms.

The HRDF requires firms to spend a minimum amount on training or loose their levy contribution, thus creating incentives for firms to train rather than "poach" skilled workers from other employers. It offers different schemes that give employers flexibility in training in-house, or using a variety of external public and private sector providers including second-tier public-private intermediaries such as statelevel skill development centers. This funding had the additional effect of creating a vibrant training market, with public and private sector providers competing for resources. It addresses information constraints through public information campaigns, subsidized delivery of training need assessments (TNAs) to small and medium enterprises (SMEs), certification of training providers and wide dissemination of their offerings, and electronic billing to keep employers informed of their levy use status. Recognizing the funding constraints of SMEs, the HRDC enlists certified providers to act as its agents, collecting from users the fees for which firms are responsible and claiming the reimbursable balance from HRDF, thus reducing up-front cash outlays from SMEs.

Source: Tan (2000)

Market failures diminish employer incentives to train and the appropriate policy response will depend on the nature of the market failure. While not Russia-specific, available WBES data suggest that three market failures-high cost of training, training externalities from turnover of skilled workers, and information problems - are key constraints for training. Financial sector reforms to improve access to funding for all kinds of investments, including training, are likely to be most important for smaller enterprises. When poor information is the constraint, the appropriate policy response is to disseminate widely the evidence on the productivity benefits of training, best practices in training know-how, and information about the availability, offerings and cost of services 
from different public and private sector training providers. And when employer incentives to train are low because of turnover or "poaching" of skilled workers by other employers, mandates or collective action to get all firms to train can help internalize some of these externalities from training. The Human Resource Development Fund of Malaysia is one example of such a training policy and it has, since its introduction in the mid-1990s, successfully increased training among firms (see Box 6). ${ }^{28}$

\section{Box 7. International Experience with Training Payroll Levies}

International experience with training payroll levies suggests that the following factors must be borne in mind:

- Employers buy-in for any schemes is crucial. For a scheme to be successful, governments should ensure that employers are consulted at an early stage and are involved in designing, implementing and evaluating the fund.

- Funds collected must be earmarked for training. In some countries, funds are comingled with general revenues and used for other purposes.

- Administrative efficiency and transparency is critical. High compliance is essential. There should be an effective collection mechanism. Claims should be processed and reimbursed efficiently. Procedures for disbursing funds should be clear and transparent (the Singapore Skills Development Fund and the Malaysian scheme are examples). However, all schemes have significant non-compliance-over one-third of employers in Malaysia do not comply mainly because they find the regulations burdensome. In countries with poor administrative capacity, non-compliance can be especially high, particularly among small businesses.

- Schemes should not crowd out non-governmental providers. Crowding out has been observed in some countries, especially where revenues are directly channeled, if only partly, to public training institutions. Government and non-government providers should compete on a level playing field for funds. Competition should increase the effectiveness and efficiency of public institutions. The government should ensure quality control among all training providers. Only providers (including public providers) of good quality and relevant training should be able to access funds.

Source: Canagarajah, Dar and Murphy (2003)

The Russian government should consider putting in place employer-targeted training policies to remedy the under-investment in in-service training. In doing so, it can draw on the experiences of many other countries, both industrialized and developing, that have

${ }^{28}$ Taiwan (China) and Singapore are two other East Asian economies that have successfully used direct reimbursement of approved training expenses, funded through payroll levies, to encourage firms to train their employees. The introduction of a training grant scheme in Taiwan (China) led to dramatic increases in training, which continued after the program ended in the 1970s. Singapore used a levy on the wages of unskilled workers to finance training grants to employers to upgrade worker skills. The Skills Development Fund's aggressive efforts to raise awareness of and direct training among firms led to a steady rise in training, especially among smaller firms. See Tan (2000) for an extended discussion of the Malaysian experience and an impact evaluation of the HRDF policy. 
used a variety of policy interventions such as payroll-levy training funds, tax incentives for employer-sponsored training, and matching grants to address similar underinvestment in workforce skills. Designing a training policy appropriate to Russia is beyond the scope of this chapter, but the global experience with training levies (see Middleton, Ziderman and Adams 1993; Gill, Fluitman and Dar 2000) suggests several lessons for the Government of Russia (see Box 7). Essentially, they suggest: (a) that employers should be closely involved in the governance of levy funds, as in the cases of Argentina, Brazil and Chile which have vested supervision of levies in industrial bodies; (b) that policies be designed to increase competition in training provision from all providers, both public and private including the employer; and (c) that levy funds be strictly earmarked for training, and not diverted to other government uses as has happened with training levies in several Latin American and African countries.

Although international evidence shows that levy schemes can have a positive impact by increasing training by enterprises, they are not without problems. Levies have been inequitable in the sense that large employers have tended to benefit more from training levies than have small or medium-size employers. Employer reactions to the schemes have also been mixed, with many firms, especially smaller businesses, feeling that a levy is simply another tax from which they rarely benefit. This may also be the response of many Russian firms that already face relatively high payroll taxes, unless they are reassured that funds earmarked for training are not diverted elsewhere, and that training funds are capably and transparently implemented.

Training levies do not work particularly well for small and medium enterprises (SMEs), the group of enterprises in Russia that exhibited the lowest incidence and intensity of inservice training. The experiences of China, Malaysia, Brazil and Chile suggests that SME take-up of training policies in their countries are low, and that SME-targeted training programs are required to reach SMEs. Encouraging training in SMEs may require more proactive approaches to address systemic weaknesses in both training and technological capabilities and access to finance that most SMEs face. Mexico's experience with SME training programs offers some lessons (see Box 8).

An alternative is to use matching grants schemes, which can help to develop a training culture although, by themselves, they will not expand the training market. The most successful matching grant schemes are demand-driven, implemented by the private sector, and aim to create sustained training markets. Chile and Mauritius report positive results by using private agents to administer their schemes, and an increased investment in training matched by a reduction in enterprise failure. A side benefit has been the development of a network of industry management training consultants who are available to enterprises that want to invest in enterprise-based training. Singapore has a program to build up its stock of industry trainers, and Japan's Industrial and Vocational Training Association has trained over 30,000 industry trainers in the past 30 years. It is important to generate training capacity in enterprises and increase the propensity for workers to undertake training. Grants should not be restricted to state-run training institutions. Funds should strengthen and diversify the supply of training and stimulate demand. 
Strong training cultures have been established in Japan, Korea, and Singapore, much of Europe, and, judging by the levels of in-company training, Brazil and Chile as well.

\section{Box 8. Mexico's Proactive Training Programs for SMEs}

The Integral Quality and Modernization Program (CIMO), established in 1988 by the Mexican Secretariat of Labor, has proved effective in serving small and medium-size enterprises (SMEs). Set up initially to provide subsidized training, CIMO quickly evolved when it became apparent that lack of training was only one of many factors contributing to low productivity among SMEs. By 2000 CIMO was providing an integrated package of training and industrial extension services to over 80,000 small and medium-size enterprises each year and training to 200,000 employees. Private sector interest has grown, and more than 300 business associations now participate in CIMO, up from 72 in 1988.

All states and the Federal District of Mexico have at least one CIMO unit, each staffed by 3-4 promoters and housed in business associations which contribute office and support infrastructure. Promoters organize workshops on training and technical assistance services, identify potential local and regional training suppliers and consulting agents, both public and private, and actively seek out small and medium-size enterprises to deliver assistance on a cost-sharing, time-limited basis. They work with interested SMEs to conduct an initial diagnostic evaluation of the firm, as the basis for organizing training programs and other consulting and technical assistance. The government does not deliver this training; instead, its role is to identify the most qualified local training providers, both public and private, that can deliver the training usually on a group or association basis so as to reduce unit training costs. This strategy is deliberate since one of the program's objectives is to promote the development of regional training markets able to serve the needs of local enterprises. The CIMO program also targets industrial clusters, and works with large firms and their SME suppliers to organize and deliver cluster-specific training programs.

Several rigorous evaluations have found CIMO to be a cost-effective way of assisting SMEs. While CIMO firms tended to have lower pre-program performance than a comparison group with similar attributes, their post-program outcome indicators tended to show relative improvements in key outcome indicators like labor productivity, capacity utilization, product quality, wages and employment.

Source: Tan et al (2004).

Whatever training policy is eventually adopted in Russia, it is imperative that enterprises and employer associations have meaningful inputs into the design of the policy so that the training system is responsive to their needs and those of other key stakeholders. Where warranted, industry could take joint responsibility with government for the management and delivery of training. Brazil's experience in this case is illustrative (see Box 9).

At an institutional level, involving Russian employers in the management of individual vocational and technical institutes should help ensure a steady flow of information to these institutions of what skills are needed by local industry, as well as win-win opportunities for instructors to upgrade their knowledge and for studentes to be placed with employers. The Indian Government is taking a similar approach is its efforts to 
reform the moribund public-sector Industrial Training Institutes (ITIs). It introduced Institutional Management Committees (IMCs) in 1998 to involve employers in overseeing ITI operations, and there are now 350 IMCs in 18 states with more in the pipeline. IMCs are supported by the Confederation of Indian Industries (CII) and the Federation of Indian Chamber of Commerce and Industry (FICCI), with each IMC being chaired by a local industry representative. As currently structured, however, IMCs have limited decision making powers because most states in India do not allow ITIs significant financial authority or incentives to revamp training offerings, or to retain student fees and other non-traditional sources of revenues from, for example, delivering tailored training courses to employers.

Employers could also form public-private partnerships to deliver demand-driven, low cost training that is largely self-financing. The case of Malaysia's Penang Skills Development Centre is suggestive of how the private sector in different Russian regions can partner with state governments in the reform and management of tertiary-level professional and technical institutes (see Box 10).

\section{Box 9. Employer-Owned and Managed Training in Brazil}

Experiences in Brazil underscore the importance of ownership and employer participation. A chronic gulf between supply and demand was bridged by giving control of training to its users. The National Industrial Apprenticeship Service (Serviço Nacional de Aprendizage Industrial [SENAI]) was created in the 1940s and operates under the ownership of the Federation of Industries. SENAI was followed by four other sector-specific services: commerce (SENAC), rural areas (SENAR), small enterprises (SEBRAE), and transport (SENAT). All the services operate under the same basic structure and legal framework. Chambers of employers finance their training programs through a one percent payroll levy and run the services with full independence and under private sector statutes.

The five services have evolved in different directions although they operate with the same rules and legal framework. SENAI has a network of 500 training institutions and trains two million workers a year. SENAR and SEBRAE were first created as government bureaucracies but this led to inefficiencies, lack of responsiveness and flexibility, and to political spoils. They were recreated with ownership, management, and budgets given to the relevant employer associations. Because training markets had already been developed in the country, the rejuvenated SENAR and SEBRAE opted to buy training in the market rather than to establish their own training institutions. SENAT, the newest service, took a different path. It created an extensive satellite network for training employees of more than 1,000 firms throughout the country.

Source: Inter American Development Bank, IADB (2005) 


\section{Box 10. Industry-Government Cooperation: The case of the Penang Skills Development Centre (PSDC)}

The Penang Skills Development Centre (PSDC) is a joint company training centre established with government support. It has evolved to become a full private further education institution providing certificate and diploma level training. The Malaysian Government invests in the Centre and uses it to carry out public training programs. It demonstrates the potential of private education and training institutions being used for public training purposes where these are not viable in themselves as private commercial undertakings, and without creating the facilities in the public sector. PSDC, with more than 100 member companies, runs both standardized and customized programs. It charges at cost and is basically self-financing. Companies recoup the expenditure from the Human Resource Development Fund (HRDF), a training fund financed by a 1 percent levy on payrolls.

The initiative for PSDC came from the Penang State Government. The State provided the land and buildings. The founder members included large multinational companies with training traditions of their own. Members donate equipment, laboratories, training modules and trainers. They have access to shared training facilities without having to duplicate with their own in-house capability. SMEs enjoy technology transfer from and can benchmark their standards against multinationals. Multinationals, in turn, receive better support services. Vendors donate equipment to familiarize the company workforce with their products and promote sales.

While still a joint-training centre, the PSDC has taken on institutional functions to provide training for school-leavers and has moved to become a professional training entity in its own right. None of this is to say that the PSDC is easily replicated. Eleven other Malaysian States (out of 13) have launched similar centers, with varying degrees of success, usually a function of state government commitment, regional growth, and private sector ingenuity (the State of Johor invited equipment suppliers in the stock and update equipment used in the JDC, so training equipment was always current and comparable to those used in companies). As usual, the success of this sort of enterprise depends on a number of circumstances, most importantly the people initiating and managing the process. Centers like PSDC cannot be imposed; they need to grow in already fertile ground.

Source: Pillay (2005) 


\section{REFERENCES}

Acemoglu, D, and J. Pischke, 1998. "Why Do Firms Train? Theory and Evidence." Quarterly Journal of Economics 113 (1): 79-119.

Barro, R.J., and J.W. Lee. 2001. "International Data on Education Attainment: Updates and Implications." Oxford Economic Papers 53, 541-563.

Bartel, Anne, and Frank Lichtenberg. 1987. "The Comparative Advantage of Educated Workers in Implementing New Technology" The Review of Economics and Statistics 69 (1): 1-11.

Batra, Geeta and Andrew Stone. 2004. "Investment Climate, Capabilities and Firm Performance: Evidence from the World Business Environment Surveys". Investment Climate Department, Washington, DC: World Bank.

Becker, Gary. 1976. The Economic Approach to Human Behavior, University of Chicago Press.

Bell, Martin, and Keith Pavitt. 1992. "Accumulating Technological Capability in Developing Countries." Paper presented at the Annual Bank Conference on Development Economics, Washington, DC: World Bank.

Blom, Andreas, Lauritz Holm-Nielsen, and Dorte Verner. 2001. "Education, Earnings and Inequality in Brazil: 1982-1998: Implications for Education Policy." World Bank Policy Research Working Paper No. 2686. Washington, DC: World Bank.

Canning, Mary, Maree Bentley, Johannna Crighton, Isak Froumin, Martin Godfrey, Dorota Holzer, Stephen Kerr, Andrei Markov and Kirill Vasiliev. 2004. "The Modernization of Education in Russia". Washington, DC: World Bank.

Dar, Amit, Sudarshan Canagarajah, and Paud Murphy. 2003. Training levies: rationale and evidence from evaluations. Washington, DC: World Bank.

Dearden, L., Reed, H., and J. Van Reenen. 2000.Who gains when workers train? Training and corporate productivity in a panel of British industries. IFS working paper W00/04, London: The Institute for Fiscal Studies.

Enos, J.L. 1962. Petroleum progress and profits: A history of process innovation. Cambridge, MA: MIT Press.

Fleisher, Sabirinova and Wang. 2004 Returns to Skills and the Speed of Reforms: Evidence from Central and Eastern Europe, China, and Russia. William Davidson Institute (WDI) - Working Paper No. 703.

Fretwell, David, and Anthony Wheeler. 2001. "Russia Secondary Education and Training," World Bank Secondary Education Series. Washington, DC. 
Gill, I., Fluitman F., and A. Dar. 2000. Matching skills to market and budgets. Oxford University; Washington, DC: World Bank.

Gimpelson, V. 2004. "Qualifications and Skills Shortage in the Labor Market: Lack of Supply, Demand Constraints, or False Signals of Employers?" HSE Working Paper WP3/2004/01, Moscow.

Lazareva, Olga, Irina Denisova, and Serguey Tsukhlo (2006), "Hiring or Retraining: Russian Firms' Experience”, HSE Working paper WP3/2006/11, Moscow.

Middleton, John, Adrian Ziderman, and Arvil Van Adams. 1993. Skills for Productivity. New York: Oxford University Press for the World Bank.

Pillay, G. 2005. Malaysia: The Vocational Education and Training System. Working Paper, Washington, DC: World Bank.

Pop-Eleches, C., V. Gimpelson and E. Tesluk. 2005. "Poverty and the Labor Market". Mimeo, Washington, DC: World Bank.

Riboud, Michelle, Yevgeniya Savchenko and Hong Tan. 2006. Globalization and Education and Training in South Asia, forthcoming June 2007, World Bank book.

Rutkowski, Jan, and Stefano Scarpetta. 2005. Enhancing Job Opportunities in Eastern Europe and the Former Soviet Union. Washington, DC: World Bank.

Sabirianova, Klara. 2001. "The Great Human Capital Reallocation: A Study of Occupational Mobility in Transitional Russia." EERC Working Paper Series, EERC Research Network, Russia and CIS.

Schultz, Theodore. 1975. "The Value of the Ability to Deal with Disequilibria." Journal of Economic Literature 13 (3): 827-46.

Tan, Hong and Gladys Lopez-Acevedo. 2003. "Mexico: In-firm training for the Knowledge Economy.” WP\# 29571, Washington, DC: World Bank.

Tan, Hong, Pei Zhu and Yevgeniya Savchenko. 2003. "Enterprise Training in Developing Countries: Evidence from Investment Climate Surveys”, unpublished World Bank Institute working paper.

Tan, Hong. 1980. Human Capital and Technological Change: A Study of Japanese Wage Differentials in Manufacturing. Ph.D. Thesis, Yale University, New Haven.

Tan, Hong and Geeta Batra, 1995. Enterprise Training in Developing Countries: Incidence, Productivity Effects, and Policy Implications. PSD Department Monograph, Washington, DC: World Bank.

Tan, Hong. 2000. Malaysia Skills Needs Study. World Bank Institute, Washington DC. 
Tan, Hong. 2005. The Skills Challenge of New Technology: Training, Technology, and Productivity Growth in Malaysian Manufacturing in the 1990s. joint World BankUNDP-EPU book, Washington, D.C.

World Bank. 1997. Malaysia: Enterprise Training, Technology, and Productivity. Country Study. Washington, DC: World Bank.

—. 2003. "The Russian Labor Market: Moving from Crisis to Recovery", a copublication of World Bank and Izdatelstvo Ves Mir.

- 2004. "Malaysia: Firm Competitiveness, Investment Climate and Growth." Report No. 26841-MA, Poverty Reduction, Economic Management, and Financial Sector Unit, East Asia and Pacific Region. Washington, DC: World Bank.

—. 2005a. Brazil Investment Climate Assessment. Washington, DC: World Bank.

- 2005b. Malaysia: Firm Competitiveness, Investment Climate and Growth. Report No. 26841-MA, East Asia and Pacific Region, Washington, DC: World Bank..

. 2006. Doing Business in 2006: Creating Jobs. Washington, DC: World Bank. 


\section{Annex 1.}

\section{Estimating the Productivity and Wage Effects of Endogenous Training}

Thus far, the production function and wage models have been estimated by simple regression methods that assume implicitly that training is exogenously given. If the firms that choose to train differ systematically from those that do not (in their underlying productivity), then simple estimates of the productivity (or wage) outcomes of training may be biased. To address this potential problem, a two-stage "treatment effects" model is used where the endogenous training decision and training outcomes are estimated jointly. In this model, any in-service training is predicted from a first-stage auxiliary training equation ${ }^{29}$ and its predicted value included in the second-stage production function or wage model. ${ }^{30}$

In-service training continues to be associated with positive productivity and wage outcomes when account is taken of the endogenous training choice. In results not reported here, the selectivity-corrected training variable continues to be positively associated with productivity and wages (significant at either the 5 or 10 percent levels). ${ }^{31}$ Simulations using the estimated coefficients suggest that, for a representative firm (with the sample means for all variables), in-service training increases productivity levels by 6 percent and monthly wages by 9 percent. These findings, though supportive of the hypothesized positive training-productivity and training-wage links, should nonetheless be treated with caution and not be interpreted as being causal (panel data are needed to establish causality). However, several panel studies for industrialized and developing countries have found empirical evidence that training leads to improved future firm performance and higher wages. ${ }^{32}$

\footnotetext{
${ }^{29}$ The training equation uses the same model specification as that used in the incidence of training results reported in Table 5.

${ }^{30}$ This two-stage procedure requires that instrumental variables be found to identify the training and outcome equations. When training involves multiple choices, such as the decision of whether to train inhouse or to get training from external sources, the estimation increasingly becomes empirically intractable. As such, production function and wage model estimates for other training measures continue to rely on simple OLS regressions.

${ }^{31}$ The two-stage procedure leads to increases in the estimated coefficients of training that seem, on the surface, to be implausibly large. Other training studies report similar findings when attempting to control for selection bias in training decisions (see Dearden, Reed and Van Reenen, 2000). A more reasonable way to interpret the results is through simulations of predicted outcomes with and without training.

${ }^{32}$ Panel studies, based on longitudinal firm surveys that elicited repeated information on the training practices of the same firms, have found evidence that training, especially when it is repeated, leads to higher productivity growth and wages (see Dearden, Reed and Van Reenen 2000 for Britain; Tan 2000 for Malaysia; Tan and Lopez-Acevedo 2003 for Mexico).
} 